\section{All102 b60147}

NATL INST OF STANDARDS \& TECH R.I.C.

A11102660149

REFERENLE

Phan, Long T/Punching shear resistance O

Punching Shear Resistance of Lightweight Concrete Offshore Structures for the Arctic: Planning of Experimental Study

Long T. Phan

H.S. Lew

David I. McLean

U.S. DEPARTMENT OF COMMERCE

National Bureau of Standards

Center for Building Technology

Gaithersburg, MD 20899

July 1986

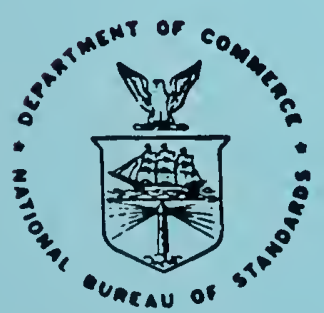

U.S. DEPARTMENT OF COMMERCE

NATIONAL BUREAU OF STANDARDS

QC

100

.056

$86-3440$

1986 

PUNCHING SHEAR RESISTANCE OF

LIGHTWEIGHT CONCRETE OFFSHORE

STRUCTURES FOR THE ARCTIC:

PLANNING OF EXPERIMENTAL STUDY

Long T. Phan

H.S. Lew

David I. McLean

U.S. DEPARTMENT OF COMMERCE

National Bureau of Standards

Center for Building Technology

Gaithersburg, MD 20899

July 1986

U.S. DEPARTMENT OF COMMERCE, Malcolm Baldrige, Secretary NATIONAL BUREAU OF STANDARDS, Ernest Ambler, Director 



\section{ABSTRACT}

This report outlines the planning for the experimental phase of an investigation currently being conducted at the National Bureau of standards to study the punching shear behavior of heavily reinforced, thick, lightweight concrete plates and shells. The test specimens are representative of structural elements used in Arctic offshore structures. The planning includes selecting dimensions and boundary conditions, materials, reinforcing ratios and patterns, and loading procedures for the test specimens such that behavioral similarity in punching shear is achieved between representative prototype Arctic structures and the scaled models. Several factors which are considered to affect the punching shear behavior of the prototype structures will be studied.

Key words: Arctic structures, experimental study, lightweight concrete, prestressing, punching shear, reinforced concrete, scale models. 



\section{PREFACE}

A project to study the performance of offshore concrete structures in the Arctic environment was initiated at the National Bureau of Standards. An initial experimental program to study the punching shear behavior of lightweight concrete offshore structures was developed with the support of the following organizations:

- The Minerals Management Service, Department of the Interior;

- Chevron Corporation;

- Exxon Production Research Company;

- Mobil Research and Development Corporation;

- Sohio Petroleum Company; and

- Shell oil company.

The authors gratefully acknowledge the cooperation, support, and guidance provided by an advisory group formed by the project sponsors.

Any opinions, findings, and conclusions or recommendations expressed in this report are those of the authors and do not necessarily reflect the views of the sponsors of this project. 


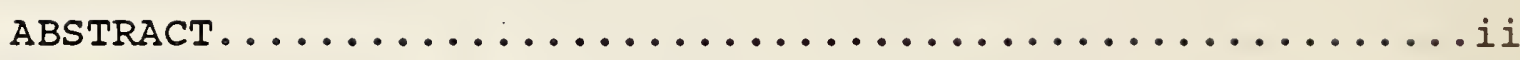

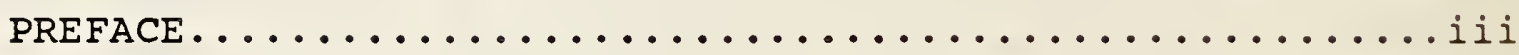

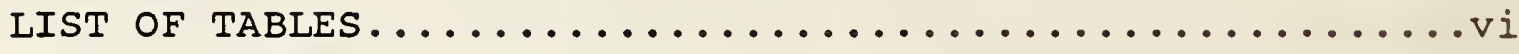

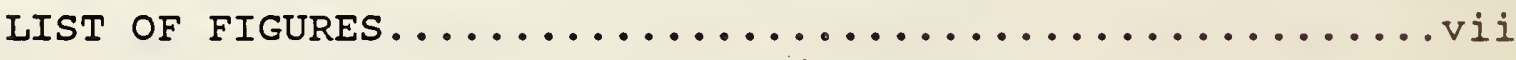

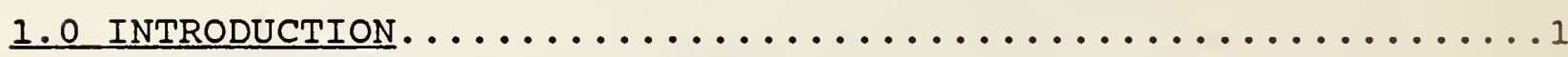

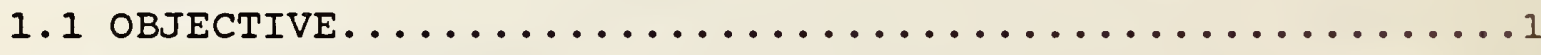

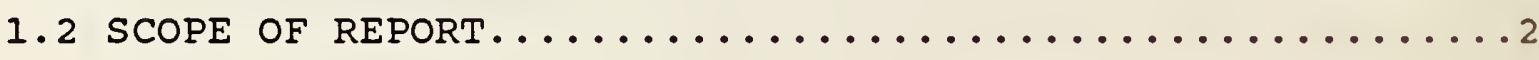

2.0 DESIGN OF FULL-SCALE SPECIMENS $\ldots \ldots \ldots \ldots \ldots \ldots \ldots \ldots$

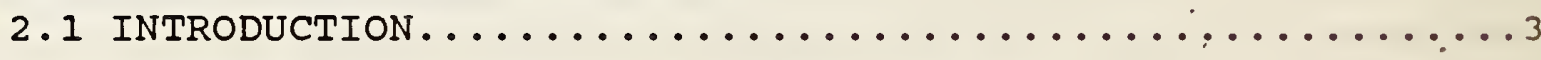

2.2 GEOMETRY AND DIMENSIONS OF FULL-SCALE SPECIMENS........

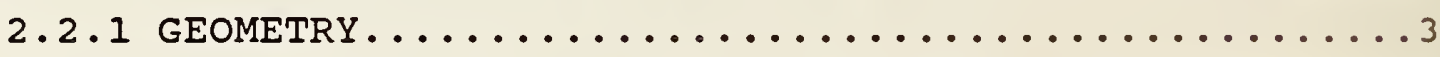

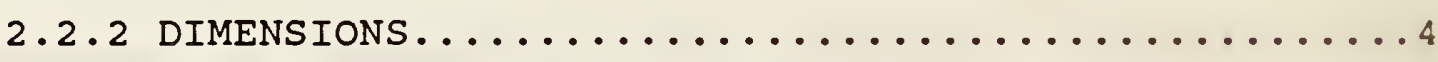

2.2.2.1 Criteria For selecting specimen

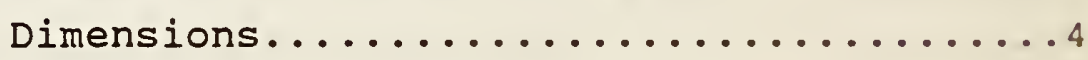

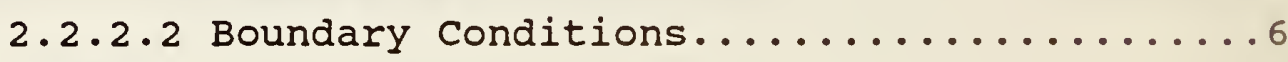

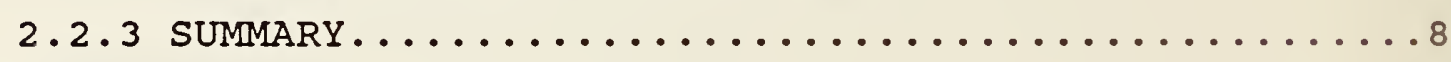

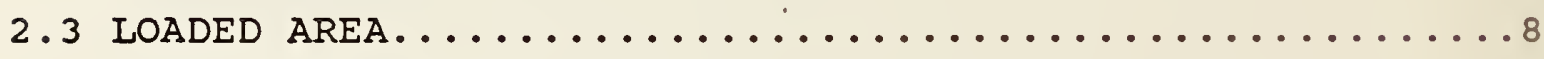

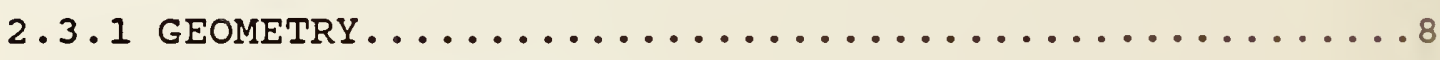

2.3 .2 SIZE OF LOADED AREA..................

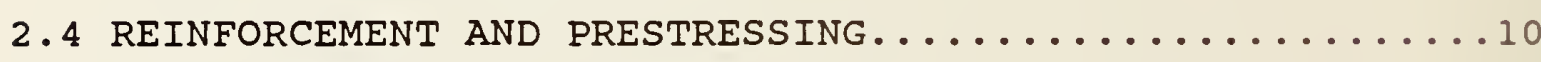

2.4 .1 REINFORCING RATIOS.....................

2.4.1.1 Flexural Reinforcement............11

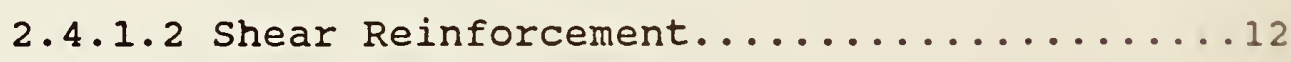

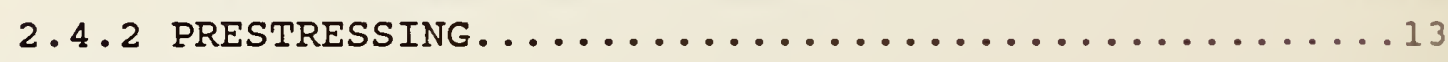

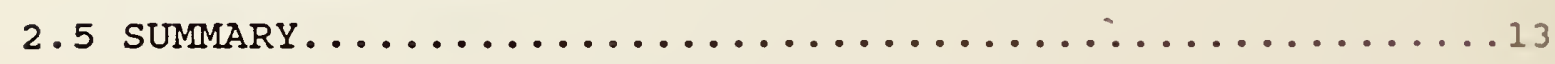




\section{TABLE OF CONTENTS (Continued)}

3.0 MODEL. . . . . . . . . . . . . . . . . . . . . . . 14

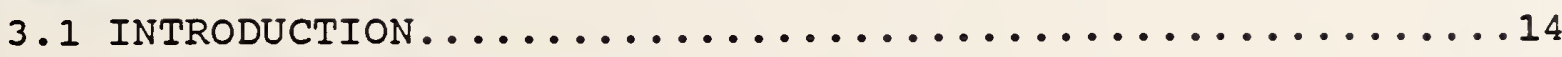

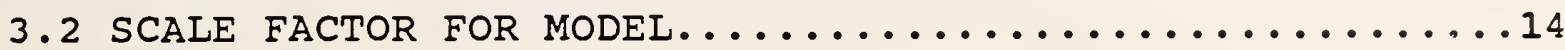

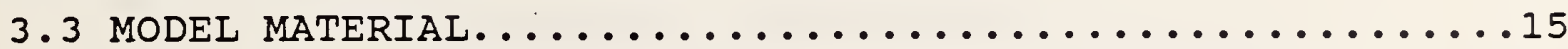

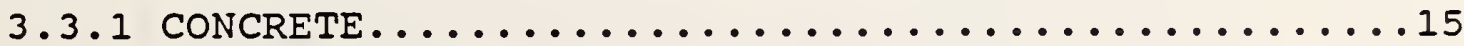

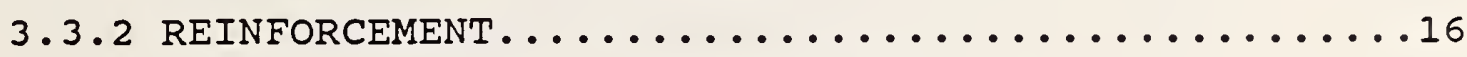

3.3.2.1 Flexural Reinforcement.............16

3.3.2.2 Shear Reinforcement...............17

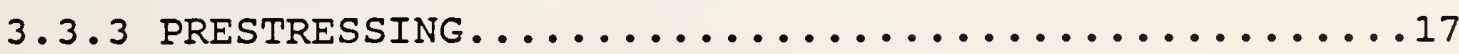

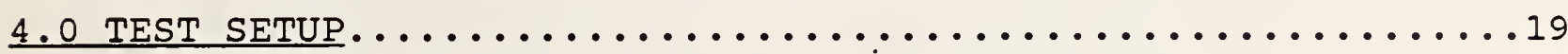

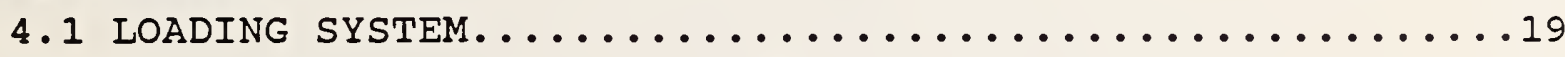

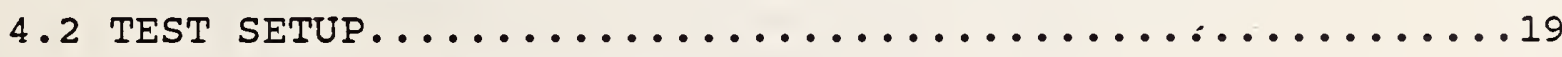

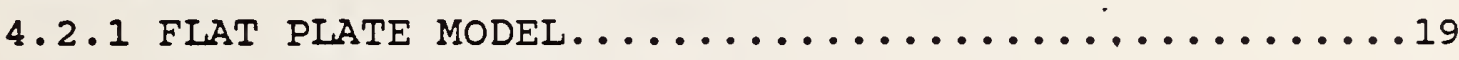

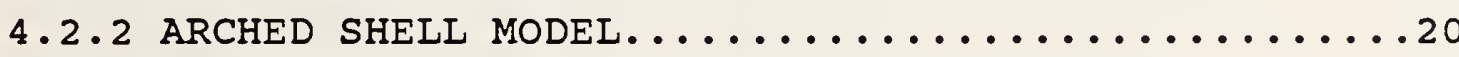

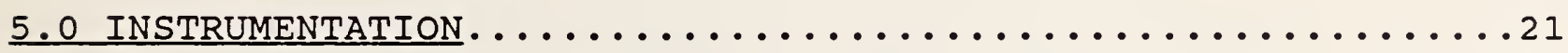

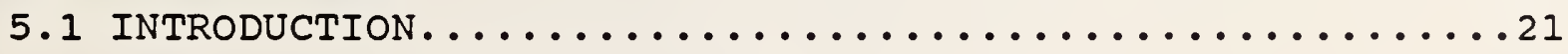

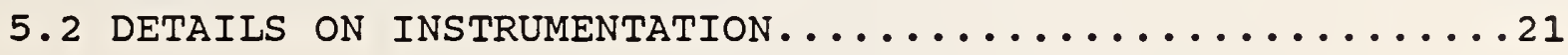

6.0 PROPOSED TESTING PROGRAM $\ldots \ldots \ldots \ldots \ldots \ldots \ldots \ldots \ldots \ldots \ldots$

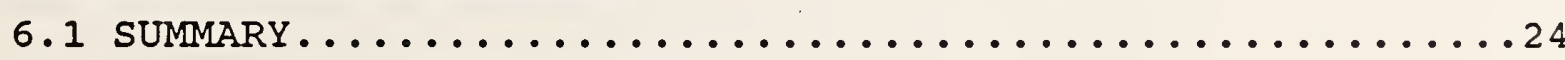

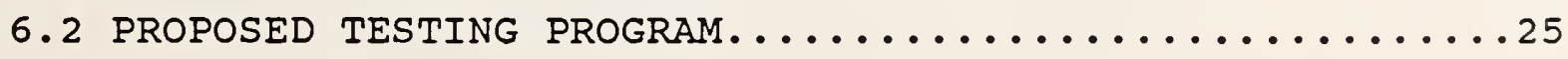

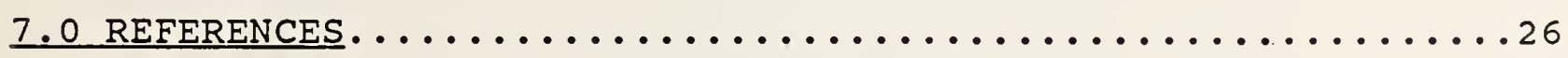




\section{LIST OF TABLES}

TABLE

Page

1 Predicted Flexural and Punching Shear

Capacities of Plate and shell specimens...........28

2 Scale Factor For Modeling Reinforced

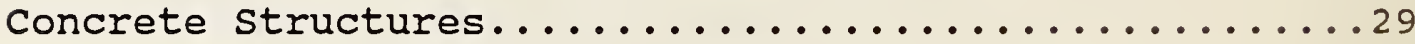

3

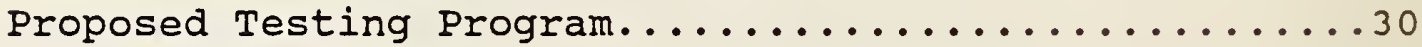




\section{LIST OF FIGURES}

FIGURE

Page

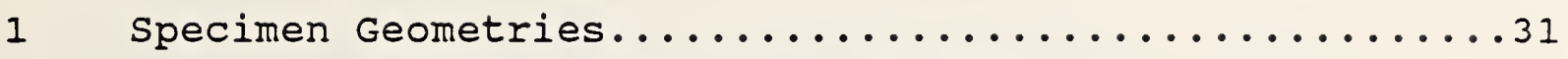

2 Modeling of Transverse Dimension of

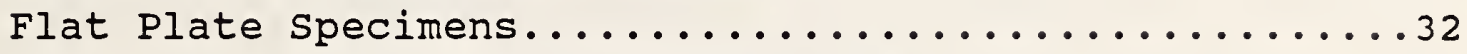

3 Modeling of Transverse Dimension of

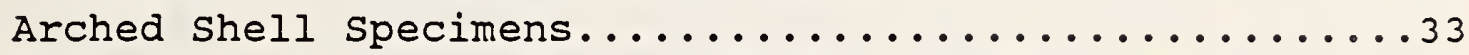

4 Modeling of Supporting Bulkheads for Flat Plate

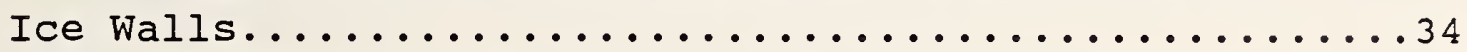

5 Span Moment in Three and Five-Span Flat Plates.......35

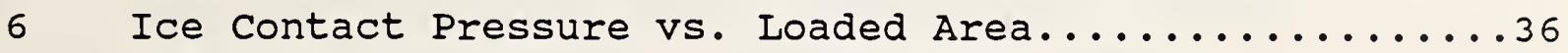

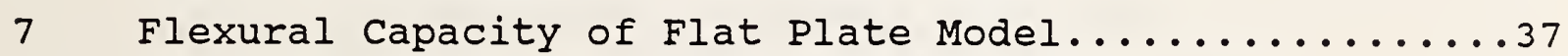

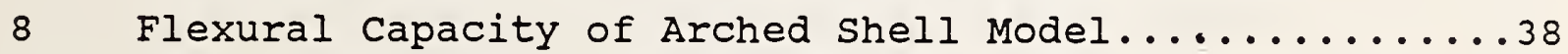

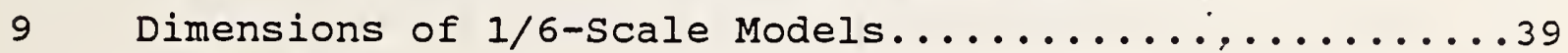

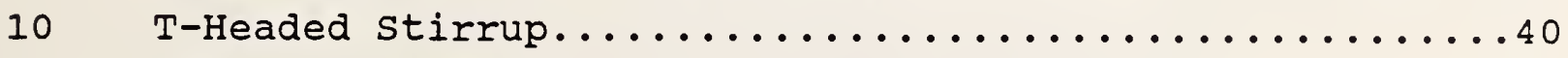

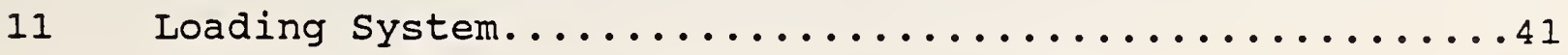

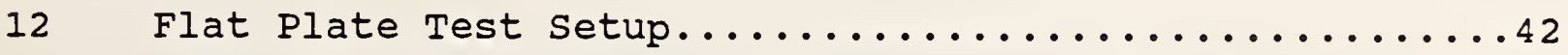

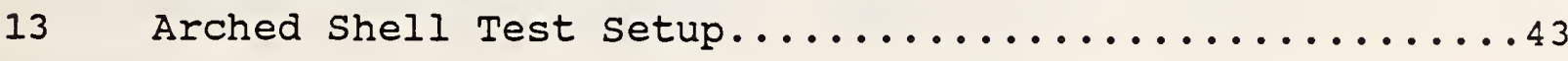





\subsection{OBJECTIVE}

This report is the second in a series of progress reports on the punching shear study being conducted at the National Bureau of standards. This study, which includes both analytical and experimental work, is aimed at developing more rational punching shear design criteria for lightweight concrete offshore structures for Arctic environments.

The main objective of this report is to describe the planning of an experimental program to study punching shear behavior in heavily reinforced, thick, lightweight concrete plates and shells subjected to high intensity concentrated loads. The experimental program will include testing a number of reduced-scale models representative of portions of ice walls of Arctic offshore structures.

The selection of the following experimental factors will be discussed:

a) Geometry, dimensions, and boundary conditions of the fullscale specimens.

b) Scale factor and materials used for models.

c) Reinforcement ratios and prestress force to be used in the models.

d) Area and method of loading.

e) Instrumentation, and data acquisition.

Variables to be examined in this study will include:

- Area of loading

- Radius-to-thickness ratio (R/t)

- Shear reinforcement ratio

- Effect of multiple span

- Effects of prestressing 


\subsection{SCOPE OF REPORT}

Chapter 2 outlines the criteria for selecting the full-scale specimens.

Chapter 3 discusses the selection of the scale factor and materials used for the models.

Chapter 4 describes the loading system and the test setup for model testing.

Chapter 5 describes the instrumentation that will be used to collect data.

chapter 6 summarizes the experimental program. A testing program for the models is proposed. 


\subsection{DESIGN OF FULL-SCALE SPECIMENS}

\subsection{INTRODUCTION}

The selection of the cross sectional shapes of the full-scale specimens, their dimensions and boundary conditions, and the area of loading are discussed in this chapter. The term full-scale specimen will be used to refer to the portion of a prototype Arctic structure that will be isolated and scaled down for testing. These selections were made so that the punching shear behavior between the full-scale specimens and the Arctic offshore structures would be the same for a given loading condition. Linear elastic finite element analyses were used in this selection process. Therefore, the results of the analyses would be valid only in the elastic range.

\subsection{GEOMETRY AND DIMENSIONS OF FULL-SCALE SPECIMENS}

\subsubsection{GEOMETRY}

The test specimens geometries were selected based on typical configurations (see Fig. 1) of existing and proposed designs of concrete offshore structures $[2,7,10,11,12,13,14]$ having exterior walls or ice walls.

A typical ice wall is generally supported by a combination of bulkheads and thrust beams to enhance its resistance to ice pressures. The concrete segments between the two supporting bulkheads are flat plates or arched shells. Two geometries- a flat plate and an open cylindrical shell with two radius-tothickness ratios $(R / t)$ of 6 and 12 - were selected for this study. Arch action induces compression in shells and thereby enhances its punching shear strength by minimizing principal tensile stresses. The contribution of arch action to punching shear resistance in shells is dependent on the $\mathrm{R} / \mathrm{t}$ ratio of the shells. 


\section{2 .2 DIMENSIONS}

2.2.2.1 Criteria For Selecting Specimen Dimensions

The criteria for selecting the thickness, span length, and transverse length of the full-scale specimen are discussed in this section.

a) THICKNESS: The thickness is uniform for all specimens and was selected based on typical thicknesses of existing and proposed designs of Arctic ice walls. A review of the literature on Arctic offshore structures [10] indicates that the ranges of typical thicknesses are on the order of 2 to $5 \mathrm{ft}$, with the larger thicknesses in flat plate ice walls.

Based on this information, a uniform thickness of 42 in ( $1 \mathrm{~m}$ ) was selected for the flat plate specimens and a thickness of 30 in $(0.8 \mathrm{~m})$ was selected for the arched shell specimens.

b) SPAN LENGTH: The span length of a specimen is defined as the spacing between two supporting bulkheads. Typical span lengths of existing and proposed designs of Arctic offshore structures range from 15 to $25 \mathrm{ft}(4.6$ to $7.6 \mathrm{~m})$. For this study, a span length of $20 \mathrm{ft}(6 \mathrm{~m})$ was selected as the span length for all full-scale specimens.

c) TRANSVERSE LENGTH: In this report, the term transverse length denotes the vertical dimension of the ice walls. A transverse length for the test specimens must be selected so that the behavior of the test specimen in the region of loading will be similar to the behavior of an actual Arctic ice wall, which typically has vertical dimensions of $40 \mathrm{ft}(12 \mathrm{~m})$ or larger. This vertical dimension is the distance between thrust beams or the distance from the top to the bottom of a wall. The 
transverse length of the full-scale specimens is determined so that when structures with different transverse dimensions are subjected to a concentrated load, the bending moments in the region around the loaded area are the same. The smallest transverse length for which the bending moments in the test specimen converge to those calculated for an actual structure was determined by the following procedure:
A series of three-span plates having different transverse lengths were analyzed. The results are shown in figure 2. It can be seen that a three-span plate having a transverse length $(2 \mathrm{~L})$ of $28 \mathrm{ft}(8.5 \mathrm{~m})$ revealed only about a $3 \%$ difference in bending moments in the localized region around the loaded area as compared to plates having transverse lengths. of $40 \mathrm{ft}$ or larger. This insignificant difference in moments indicates that a three-span plate with a transverse length of $28 \mathrm{ft}(8.5 \mathrm{~m})$ can be considered sufficient to represent the very large vertical dimension of a typical ice wall. The 28 feet $(8.5 \mathrm{~m})$ transverse length was therefore selected as the transverse length for all the flat plate test specimens.

The same criterion and procedure used in selecting the transverse length of the flat plate specimens were used to select the transverse length of the shell specimens. A series of single span arched shells with different transverse lengths were analyzed and the results are shown in figure 3. About $3 \%$ difference in bending moments in the vicinity of the loaded area can be observed for the shell of $28 \mathrm{ft}(8.5 \mathrm{~m})$ transverse length and the shell with infinite transverse length. The transverse dimension of $28 \mathrm{ft}(8.5 \mathrm{~m})$ was therefore selected as the transverse length of all arched shell specimen. 
2.2 .2 .2 Boundary Conditions

FLAT PLATE SPECIMENS: For the flat plate test specimens, two boundary conditions are considered:

(1) Boundary conditions to simulate the supporting bulkheads, and

(2) The number of spans needed to sufficiently represent a multi-span structure in the horizontal direction of a flat plate ice wall.

- Boundary Condition for Bulkheads:

A unit width of a five-span section of a flat plate ice wall with equal span lengths of $20 \mathrm{ft}(6 \mathrm{~m})$ was analyzed, to study the differences in bending moments for the following two cases:

- Case 1: Supporting bulkheads are represented as actual structural members with realistic dimensions.

- Case 2: supporting bulkheads are idealized as pin supports.

A concentrated load was applied at the center of the middle span and distributions of bending moments along the five-span beams were plotted for both cases as shown in figure 4. The comparison shows that the differences in moments between the two cases are insignificant (less than 3\%), indicating that modeling the supporting bulkheads as pin supports for the flat plate test specimen is reasonable.

\section{- Number of Spans:}

In order to select the number of continuous spans which would represent the behavior of the actual structure, a five-span 
simply supported flat plate was analyzed to examine the localized behavior. It was assumed that a five-span plate would reasonably represent continuous multi-span behavior. A uniform pressure was applied over a small area at the center of the middle span of the five-span plate.

The analysis showed that lines of zero moment exist in the two spans adjacent to the middle span. These lines are located at 16 feet $(5 \mathrm{~m})$, or 0.8 times the span length, away from the supports of the middle span. Based on this observation, a simply supported three-span plate was analyzed for the same loading condition. The center span was $20 \mathrm{ft}(6 \mathrm{~m})$ long and the two outer spans were $16 \mathrm{ft}(5 \mathrm{~m})$ long. The distribution of bending moments obtained from the three-span plate analysis were compared with that obtained from the five-span plate analysis. This comparison, shown in figure 5, indicates that there is less than one percent difference in the distribution of bending moments for the two cases. Thus, a simply-supported, three-span flat plate of $20-\mathrm{ft}(6-\mathrm{m})$ central span and $16-\mathrm{ft}(5-\mathrm{m})$ adjacent spans was selected.

ARCHED SHELL SPECIMENS: The selection of boundary conditions to model supporting bulkheads and continuity in the horizontal direction for the arched shell specimens are discussed in this section.

Analyses similar to those performed for the flat plate were also carried out for the arched shell. In the analyses of the shells, the lateral stiffness provided by the supporting bulkheads had a significant influence on the distributions of moments and inplane thrusts in the loaded span of the arch. It is difficult to duplicate this influence in the laboratory unless supporting bulkheads with realistic dimensions are modeled. In addition, unlike the flat plate, no simple set of boundary conditions could be prescribed for the arched shell specimen which properly 
accounted for the multi-span nature in the horizontal direction of arched shell ice walls.

For these reasons, it was decided to study the arched shell specimens using simple boundary conditions that could easily be established both experimentally and analytically.

A pinned support, single span with a 20 -ft $(6-\mathrm{m})$ span length was selected for this study.

\section{$\underline{2.2 .3}$ SUMMARY}

A three-span continuous, simply-supported flat plate and a single-span, arched shell were selected to represent typical Arctic ice walls. The plate has a 20-ft (6-m) central span and two 16-ft $(5-\mathrm{m})$ adjacent spans and an uniform thickness of 42 in ( $1 \mathrm{~m})$. The shell is pin supported along the straight edges (transverse direction) and has an uniform thickness of 30 in 10.9 $\mathrm{m})$ and a span length of $20 \mathrm{ft}(6 \mathrm{~m})$. Both the flat plate and the arched shell specimens have transverse lengths of $28 \mathrm{ft}(8.5 \mathrm{~m})$.

\subsection{LOADED AREA}

\section{$2 \cdot 3.1$ GEOMETRY}

In this study, the geometry of the loaded area was selected so that a uniform state of stress would be achieved over the contact area of test specimens. Since a uniform state of stress is more easily achieved experimentally with a circular loaded area, a circular load was selected.

\subsubsection{SIZE OF LOADED AREA}

The size of the loaded area was selected based on the following criteria: 
(1) The contact pressure for punching shear failure to occur in the test specimens should be within the range of realistic local ice pressures.

(2) The size of the loaded area should be selected so that a punching shear failure will occur prior to flexural failure.

A relationship between the applied punching shear pressure and the loaded area can be obtained for any assumed value of nominal ultimate shear stress. This ultimate stress is assumed to act on a critical section defined by the ACI code. For a circular loaded area, as shown in figure 6 , the critical section is a circle that has its perimeter located a distance equal to half of the effective depth away from the perimeter of the loaded area [3]. Figure 6 shows that the size of the loaded area is inversely proportional to the applied pressure, i.e. if the area of loading becomes smaller, the required pressure for a punching shear failure will increase. If the area of loading is too small, the pressure at punching shear failure will become unrealistically large. However, if the loaded area is made too large, flexural failure of the specimen will occur instead of a punching shear failure.

In order to select the size of a loaded area that would satisfy the stated criteria, the following two assumptions were made:

(1) The upper-limit of a realistic value for localized ice pressure acting on an Arctic structure is approximately 3500 psi (24 MPa).

(2) The mean value of nominal ultimate shear stress acting on the critical section is assumed to vary between $9 \sqrt{f^{\prime}}$ to $15 \sqrt{f^{\prime} \mathrm{c}}$. The upper value of $15 \sqrt{\mathrm{f}^{\prime} \mathrm{c}}$ is lower than the upper limit obtained from another experimental program [1] which found that 
the nominal ultimate shear stress of normal weight, reinforced concrete plate and shell specimens ranged from $11 \sqrt{\mathrm{f}^{\prime} \mathrm{C}}$ to $18 \sqrt{\mathrm{f}^{\prime} \mathrm{C}}$. However, this value of $15 \sqrt{f^{\prime} c}$ is reasonable for lightweight concrete because the contribution of aggregate interlock to the punching shear strength of a lightweight concrete structure will be less than that of a normal weight aggregate concrete structure.

Based on these two assumptions, loaded areas ranging from 12 to $25 \mathrm{ft}^{2}$ ( 1.1 to $2.3 \mathrm{~m}^{2}$ ) are obtained using figure 6. Any loaded area within this range satisfies the stated criteria. For this experimental program, a circular loaded area of $12.5 \mathrm{ft}^{2}\left(1.2 \mathrm{~m}^{2}\right)$ was selected for the majority of the specimens, although two specimens will be tested with a circular loaded area of $25 \mathrm{ft}^{2}$ $\left(2.3 \mathrm{~m}^{2}\right)$.

\subsection{REINFORCEMENT AND PRESTRESSING}

Most Arctic offshore structures, due to their large dimensions, are built segmentally. Post-tensioning is used to connect segments of the ice wall together and to enhance punching shear strength by creating a state of triaxial compression within the wall. Also, high percentages of flexural and shear reinforcement are used in Arctic ice walls because of the high-intensity loads they are designed to withstand. In determining the reinforcement ratios and the prestressing forces for the specimens, the following two criteria were used:

(1) The reinforcement ratios and prestress force should be selected so that they are within the typical ranges used in real Arctic offshore structures.

(2) The flexural and shear reinforcement ratios should be selected so that a punching shear failure will occur prior to a flexural failure in the specimens. 


\subsubsection{REINFORCING RATIOS}

\subsubsection{Flexural Reinforcement}

Available literature on the design of Arctic offshore structures indicates that flexural reinforcement ratios range from 1.5 to 2.5 percent [10]. This ratio represents the amount of steel in one direction and on one face of the cross-sectional area of the ice wall. A previous experimental investigation on punching shear [1] concluded that differences in punching shear strength due to varying the amount of reinforcement in structures of this type is insignificant (an increase of $43 \%$ in flexural reinforcement caused only a $2 \%$ increase in punching shear strength). Therefore, flexural reinforcement was not considered as a variable in this study.

To select the ratios of flexural reinforcement for the specimen that would satisfy the stated criteria, a method developed and used succesfully in another punching shear study [1] was used in this study. The method involved obtaining design moments by averaging the peak values of elastic moments over an appropriate width [1]. The calculated design moments obtained by this averaging method were then used to establish applied loadcalculated design moment relationships for both the flat plate and arched shell specimens.

The flexural capacity curves for both the plate and the shell specimens were obtained. The shell sections were treated as columns subjected to eccentric loading. Two ratios of flexural reinforcement, 1.75 and 2.5 percent, were chosen in the specimen. These values are within the range typically used in Arctic offshore structures. The predicted flexural capacities of the specimens were obtained by superimposing the applied loadcalculated design moment relationship on the flexural capacity 
curves as shown in figures 7 and 8 . The points of intersection of these curves represent the predicted flexural strengths of the specimens. The flexural capacities of the specimens corresponding to the two chosen ratios of flexural reinforcement are summarized in table 1 . However, the 2.5 percent ratio will be used in only one specimen to examine the effect of a high flexural reinforcement ratio on the mode of failure.

\subsubsection{Shear Reinforcement}

The contribution of shear reinforcement to punching shear resistance in offshore concrete structures is one of the variables examined in this study. No rational basis currently exists for the determination of shear reinforcement ratios in Arctic offshore structures. Shear reinforcement ratios as high as 1 percent have been suggested [10]. To study the contribution of shear reinforcement to punching shear resistance, three ratios of shear reinforcement were selected: $0,0.22$, and 0.44 percent.

The punching shear strengths of the specimens were also predicted by summing the nominal shear stress acting on the critical section defined by the ACI code. The nominal shear stress acting on the critical section was assumed to be $11 \sqrt{f^{\prime} \mathrm{c}}$ for the plate specimens and $15 \sqrt{f^{\prime} \mathrm{C}}$ for the shell specimens (these assumptions were made based on the results of the experimental study conducted by BWA [1]). The results of the comparison are given in table 1. A comparison of the predicted flexural and punching shear strengths of both the plate and the shell specimens is presented in table 1 ; this comparison indicates that punching shear failure would occur prior to flexural failure in all specimens. 


\subsubsection{PRESTRESSING}

Prestressing is used in the majority of Arctic offshore structures. Prestressing values ranging from 300 to 1000 psi (2 to $7 \mathrm{MPa}$ [10] have been reported in the design of Arctic structures. The prestressing force, by creating a state of triaxial compression in the structures, is expected to have an effect on the failure load and the failure mechanism. The effect caused by prestressing specimens in one and two directions with a prestressing force of $500 \mathrm{psi}(3.5 \mathrm{MPa})$, will be studied in this experimental program.

\subsection{SUMMARY}

This chapter has presented the rationale behind the selection of the geometry and boundary conditions for flat plate and arched shell specimens to be studied in this experimental program. The selection of flexural and shear reinforcement ratios and the use of prestressing was also discussed. 


\subsection{INTRODUCTION}

It is a common engineering practice to use a reduced-scale model to predict the behavior of the larger prototype structure. A reduced-scale model has the advantages of being less costly to fabricate and test, and it does not require a large testing facility. The reduced scale model is related to the larger scale specimen by a set of similitude requirements. These requirements, if satisfied by the reduced-scale model, will allow a direct extrapolation of the behavior of the model to the larger prototype structure. The selection of the scale factor for the model specimens and the model materials will be discussed in this section.

\subsection{SCALE FACTOR FOR MODEL}

Reinforced concrete has been established as the most suitable material to be used in modeling reinforced concrete structures $[4,6]$ and therefore was selected as the model material in this study. The set of similitude requirements governing the modeling of a reinforced concrete structure using a reinforced concrete model is given in References 4 and 6 and reproduced in this report in table 2. Table 2 shows the scale factors for the different quantities for a reinforced concrete model.

It may be seen from table 2 that the similitude requirements for a reinforced concrete model are specified solely by the geometric scale factor $s_{1}$ if the stress-strain relationship of the model concrete and its elastic modulus are identical with those of the prototype. The choice of this geometric scale factor is governed by such factors as the capacity of the testing facilities, the practical dimensional limitations of the model and the cost to 
build and test the models. Taking the above factors into account, a scale factor, $s_{1}$, of 6 was selected for use in this study.

Having selected the scale factor, the overall dimensions of the models can be obtained by directly scaling down the dimensions of the full-scale specimens by a factor of 6 . Figure 9 shows the dimensions and boundary conditions of the $1 / 6$ scale models in this study.

\subsection{MODEL MATERIAL}

In general, a model material is required to have well defined properties that are similar to those of the structure being modeled. In this study, the concrete and the reinforcements used for the 1/6-scale models were selected so that certain properties possessed by the materials used for Arctic structures will be duplicated.

\section{3 .1 CONCRETE}

Theoretically, a model concrete may be produced by scaling down the sizes of all materials which compose concrete, including cement, aggregate, etc., using the geometric scale factor $s_{1}$. However, this is impractical since a finer fine aggregate has excessive water demand and more finely ground cement is not available. As a result, model concrete is proportioned as it would be for the structure being modeled. Information obtained from literature on Arctic offshore structures shows that highstrength lightweight concrete has been used extensively as the principle building material for these structures. Lightweight concrete is required for economic and practical reasons, and is achieved by using lightweight coarse aggregate with a nominal maximum aggregate size typically being $3 / 4$ in (19 $\mathrm{mm}$ ). The use of many additives, such as condensed silica fume, high-range 
water reducing agents or "superplasticizers", and air-entraining agents, is also reported. These additives are used to improve workability of the concrete $\mathrm{mix}$ and strength and durability of Arctic offshore structures which are constantly exposed to severe environmental conditions $[8,9]$. Based on this information, the following material properties were selected for the model concrete in this experimental program:

(1) A mean ultimate compressive strength f'c of at least 7,000 psi $(48 \mathrm{MPa})$ is required for the model concrete. This compressive strength will be determined by testing $4 \times 8$ in $(101 \times 203 \mathrm{~mm})$ cylinders according to recommendations of the ACI committee 444 [5].

(2) North Carolina solite aggregate with a nominal maximum aggregate size of $1 / 2$ in $(13 \mathrm{~mm})$ will be used as coarse aggregate. This size of aggregate was selected to satisfy the practical dimensional requirements.

(3) Acceptable proportions of condensed silica fume (10 percent replacement of cement), superplasticizer, and air-entraining agent will be used to achieve similarity and to improve workability of the model concrete.

\section{3 .2 REINFORCEMENT}

The 1/6-scale models will have the same ratios of flexural and shear reinforcements selected in chapter 2 for the full-scale specimens. Conventional reinforcing steel will be used for model reinforcing. The size and type of reinforcing bars are discussed in this section. 


\subsubsection{Flexural Reinforcement}

The same two ratios selected for the full-scale specimens will be used for the $1 / 6-$ scale models, 1.75 and 2.5 percent. The high percentage of flexural reinforcement and the dimensions of the $1 / 6$-scale models dictated the use of $\# 4$ ( $1 / 2$ in diameter) deformed reinforcing bars for the flat plate models and \#3 (3/8 in diameter) deformed bars for the shells. A mean yield strength of $60 \mathrm{ksi}(414 \mathrm{MPa})$ was also specified for these reinforcing bars.

\subsubsection{Shear Reinforcement}

The same three ratios of shear reinforcement, $0,0.022$ and 0.44 percent, selected for the full-scale specimens will be used in the 1/6-scale models. There is a trend in industry toward using mechanically headed stirrups as shear reinforcement in Arctic offshore structures due to the congestion of reinforcement created by high reinforcing ratios. The shear reinforcement is fabricated so that it has a $T$-shaped head at both ends that may be interlocked into the flexural reinforcing bars (see Fig. 10). Facility of construction is the main advantage of using $T$-headed bars. To achieve similarity, T-headed bars, stamped out from steel plate, with a mean measured yield stress of $52 \mathrm{ksi}$ (359 MPa) were selected for use as shear reinforcement. Typical dimensions of the T-headed bars are given in figure 10.

\section{3 .3 PRESTRESSING}

The tendons were selected to be finely-threaded bars, $7 / 8$ in (22 $\mathrm{mm}$ ) in diameter, with a yield strength of $125 \mathrm{ksi}(862 \mathrm{MPa})$. The tendons will be equally spaced across the concrete section to provide uniform distribution of 500 psi (3.5 MPa) compressive stress in the models. The use of tendons with a fine pitch of 
thread will help to minimize prestressing losses due to end anchorage slip, which otherwise can be significant due to the short length of the prestressing tendons.

Grouting of the post-tensioning ducts is usually performed in real Arctic structures to protect the post-tensioned tendons from being damaged by corrosion. However, it is believed that the absence of grout will not affect the punching shear strength of the post-tensioned structures. Therefore, the tendon ducts were not grouted in this study to simplify the construction of the test specimens.

Prestress force will be applied sequentially and monitored using a strain gage mounted on each of the tendons. It is anticipated that sequential tensioning of the tendons will result in loss of prestress due to elastic shortening of concrete, and retensioning will therefore be necessary to account for this loss. other causes of losses of prestress, such as friction loss and time-dependent losses (creep and shrinkage of concrete, relaxation of post-tensioned tendons), are considered insignificant since the tendons are straight and short and the post-tensioned specimens are to be tested shortly after being prestressed. 


\subsection{TEST SETUP}

\section{I LOADING SYSTEM}

A loading system designed to provide a uniformly distributed pressure on a circular area was selected for use in this testing program (Fig. 11).

Load produced by the NBS 12,000 kip (6,000 tons) universal testing machine is transferred to a solid steel piston contained in a steel cylinder. The cylinder also contains layers of natural rubber and leather pads. The rubber is used to simulate fluid behavior and will impart a uniform pressure on the loaded area of the model. The leather pads are used to contain the rubber within the cylinder.

Molybdenum grease was used on the inner surface of the steel cylinder during calibration tests on the loading system. It was shown that loss of applied load transmitted through the loading system due to friction was approximately 1 percent and therefore was considered negligible.

\subsection{TEST SETUP}

\subsection{FLAT PLATE MODEL}

The test setup for the three-span flat plate model and its boundary conditions are shown in figure 12. The flat plate model will be set on top of two interior supports spaced 40 in ( $1 \mathrm{~m}$ ) on center. Each of these supports consists of a $4 \times 1$ in steel bearing plate, a 3 in diameter half-round steel bar, and a w8x67 beam. At one of the two interior supports, two layers of Teflon will be placed between the bearing plate and the half-round bar to provide a friction-free surface. Similarly, the assembly of the exterior supports also consists of a $4 \times 1$ in bearing plate, 
Teflon layers, a 3 in diameter half-round bar, and a w12x53 beam. These exterior supports will be placed 32 in $(0.8 \mathrm{~m})$ away from the interior supports and on top of the specimen. They will be tied down to the test floor to prevent vertical displacements of the specimen at the exterior supports. Half-round steel bars and Teflon are used to allow rotational and horizontal displacements at the supports, simulating roller supports. For the interior support in which no Teflon is used, friction is assumed to prevent horizontal displacement and allow only rotational displacement, simulating a pin support.

\subsubsection{ARCHED SHELL MODEL}

A steel test bed has been designed for testing arched shell specimens. A schematic of the test setup is shown in figure 13.

The test bed consists of three wide flange beams (w10x60), 78 in long, placed parallel to the span direction of the shell specimens. Two cut-off beams ( $18 \times 58$ ), cut with two different angles to accomodate two $\mathrm{R} / \mathrm{t}$ ratios of the shell specimens, will be bolted onto the top flange of each of the wide flange beams to accomodate the thrust forces. Eight $7 / 8$ in-diameter $(22 \mathrm{~mm})$ bolts will be used for each connection. The wide flange beams will be tied down to floor at the center to prevent upward displacement of the test bed. A $2 \times 12$ in plate $(5 \times 30 \mathrm{~cm}), 56$ in long $(142 \mathrm{~cm})$, will be placed on each side of the test bed, connecting the three cut-off beams to provide a continuous support. 
5.0 INSTRUMENTATION

5.1 INTRODUCTION

Monitoring of the specimens during and after testing will include making the following observations and measurements:

(1) The ultimate failure load and the mode of failure.

(2) Strain in the shear and flexural reinforcement and in the prestressing tendons in the vicinity of the loaded area.

(3) Crack development and crack patterns.

(4) Deflections under the load and at points along the major axes of the test specimens.

(5) Support rotation in the shells.

\subsection{DETAILS ON INSTRUMENTATION}

The test load will be applied to the specimens incrementally using the NBS 12,000 kip capacity universal testing machine. Applied load will be monitored by the testing machine and by a 400 kip-capacity load cell. Readings of strains and displacements will be recorded at each increment of load using an electronic data acquisition system, which is capable of scanning and recording 128 data channels in $1 / 100$ of a second.

Electrical resistance foil strain gages will be used to measure strain in the shear and flexural reinforcement and in the prestressing tendons. All gages are temperature-compensating gages. The gages will be mounted on the reinforcement using an M-bond 200 adhesive and protected from moisture with layers of protective coating. 
Strain in the shear reinforcing steel will be measured using small strain gages so that they can fit onto the stem section of the T-headed bars. The gages will be placed at mid-height of the T-headed bars. Four T-headed bars with gages will be placed along the two major axes of the specimens at a distance of half of the effective depth away from the edge of the loaded area, and an additional four bars with gages will be placed at a distance equal to the effective depth. The T-headed bars with gages will be greased after they are in place so that bond stresses on these bars will be minimized. Signals received from these strain gages on the T-headed bars and flexural reinforcement will be used to determine the initiation of cracking.

During tensioning of the post-tensioning tendons; the force in the tendon will be measured using a strain gage mounted on each tendon. These gages will be the same type of gages used on the flexural reinforcement. The gages will indicate tension force in the tendon and will serve as an indicator of loss of prestress in the post-tensioning process. The gages will also provide a measure of any stress changes in the tendon during testing, although it is expected that little change will occur.

Deflections of the test specimens will be measured using linear variable differential transformers (LVDTs). Measurements will be taken on the underside of the test specimens at distances of 0 and 12 in $(30 \mathrm{~cm})$ away from the center of the specimens and at the supports.

Externally-mounted dial' gages will be used to monitor the support rotations of the shell specimens during testing. Monitoring of the support rotations will provide information on the behavior of the test setup. 
Cracks and crack patterns of the model specimens will be visually monitored during testing. After testing to failure, the specimens will be removed and sectioned in both directions, and the cracks highlighted and recorded. 


\subsection{SUMMARY}

The selection of full-scale specimens and the design of 1/6-scale model specimens of Arctic ice walls have been outlined in this report. Test specimens were selected so that the behavioral similarity between the specimens and the prototype structures was maintained. The scale factor of 6 was selected based on practical and economical reasons.

Reinforced concrete was selected as the model material. North Carolina solite with a nominal maximum size of $1 / 2$ in (13 $\mathrm{mm}$ ) will be used as the coarse aggregate. Condensed silica fume, air-entraining agent, and superplasticizer will also be used.

Reinforcing steel, with $3 / 8$ and $1 / 2$ in diameters (\#3 and \#4) and a specified yield stress of $60 \mathrm{ksi}(414 \mathrm{MPa})$ were selected for use as flexural reinforcement in the models. Two flexural reinforcement ratios of 1.75 and 2.5 percent were selected.

Three ratios of shear reinforcement, $0,0.22$, and 0.44 percent, were selected to study the contribution of the amount of shear reinforcement to the punching shear strength of the models. Theaded bars, stamped from steel plate, with a measured yield strength of $52 \mathrm{ksi}$ ( $359 \mathrm{MPa}$ ) will be used as shear reinforcement.

Two circular loaded areas of 50 and 100 square inches ( 300 and 600 square centimeter) for the 1/6-scale models were selected. Approximate failure loads and modes of failure of the 1/6-scale models were predicted based on finite element analyses. The results of the analyses indicate that all models will fail in punching shear. 


\subsection{PROPOSED TESTING PROGRAM}

The proposed test program is presented in table 3. The program consists of a series of 1/6-scale model tests. A total of 15 specimens are proposed. Of these, six are open cylindrical shells with two radius-to-thickness ratios ( $R / t$ of 6 and 12$)$. The other specimens include eight three-span continuous flat plates and one single span flat plate (model FP1). Two of the three-span continuous flat plate models (FP2-1 and FP2-3) are duplicated to check the variability of test results. The singlespan flat plate specimen will be used to study the effect of multiple span on the punching shear strength. The models are different either in configuration or properties and are designed such that the variables mentioned in chapter 1 can be examined. Following is a list of variables to be studied, and the test specimens designed to study each variable.

a) Area of loading: Models FP2-1 and FP2-2 vs. FP2-3 and FP2-4

b) Shell radius-to-thickness ratio: Models FPI vs. AS7 vs. AS8, Models AS10 vs. AS12

c) Shear reinforcement ratio: Models FP2s vs. FP3 vs. FP4, Models AS9 vs. AS7 vs. ASIl

d) Effect of multiple span: Models FPI vs. FP2-3 and FP2-4

e) Effects of prestressing:

1. One way prestress: Models FP3 vs. FP5

$$
\text { Models AS7 vs. AS10 }
$$

Models AS 8 vs. AS12

2. Two way prestress: Models FP3 vs. FP6

FP5 vs. FP6 
1. "Experimental Work on Punching Shear Resistance of Concrete Structures for the Arctic", Brian Watt Associates, Inc. AOGA project no. 152 .

2. Buslov, V.M. and Krahl, N.W. (Brown and Root Inc.), "Fifty-one New Concepts for Arctic Drilling and Production". Part 1 , Ocean Engineering, 1983.

3. American Concrete Institute, "Building Code Requirements For Reinforced Concrete", ACI Standard 318-83.

4. Sabnis, G.M., Harris, H.G., White, R.N. and Mirza, M.S., "Structural Modeling and Experimental Techniques", PrenticeHall, 1983.

5. American Concrete Institute Committee 444," "Models of Concrete Structure", SP-24, ACI, Detroit, Mich., 1970.

6. Harris, H.G., "Use of Structural Models as an Alternative to Full Scale Testing", Full-scale Load Testing of Structures, ASTM STP 702, Shriever, W.R., Ed., American Society for Testing and Materials, 1980, pp. 25-44.

7. Schlecten, J.R., Fernandes, R.L., Dolan, D.K. and Bivens, H.R.," Analysis and Design of an Ice Wall Framing System For an Arctic Drilling Structure". Proceedings 1984 offshore Technology Conference, OTC 4691, Houston, Texas.

8. Gjorv, O.E., "Durability of Concrete Containing Condensed Silica Fume", Fly Ash, Silica Fume, Slag and Other Mineral By-Products in Concrete, ACI, SP 79-36, pp. 695-702.

9. Burge, T.A., "High-strength Lightweight Concrete with Condensed Silica Fumen, Fly Ash, Silica Fume, Slag and Other Mineral By-Products in Concrete, ACI, SP 79-39, pp. 731-745.

10. McLean, D.I., Lew, H.S., Phan, L.T. and Sansalone, M., "Punching Shear Resistance of Lightweight Concrete Offshore Structures for the Arctic: Literature Reviewn, The National Bureau of Standards, 1986. 
11. Byrd, R.C., Coleman, R.K., Weiss, R.T., Boaz, I.B., Sauve, E.R. and White, R.M.,"The Arctic Cone Exploration Structure: A Mobile Offshore Drilling Unit For Heavy Ice Cover". Proceedings 1984 Offshore Technology Conference, OTC 4800, Houston, Texas.

12. Wetmore, S.B., "The Concrete Island Drilling System: Super Series (Super CIDS)". proceedings 1984 Offshore Technology Conference, OTC 4801 , Houston, Texas.

13. Gerwick, B.C., Potter, R.E. and Rojansky, M., "Development of a Structural Concept to Resist Impacts From Multiyear Ice Floes, Ridges and Icebergs". Proceedings 1984 Offshore Technology Conference, OTC 4799, Houston, Texas.

14. Bhula, D.N., Birdy, J.N. and Bruen, F.J., "Design of Concrete Gravity Structures to Withstand Concentrated Ridge and Flow Impact Loads". Proceedings 1984 Offshore Technology Conference, OTC 4708 , Houston, Texas. 


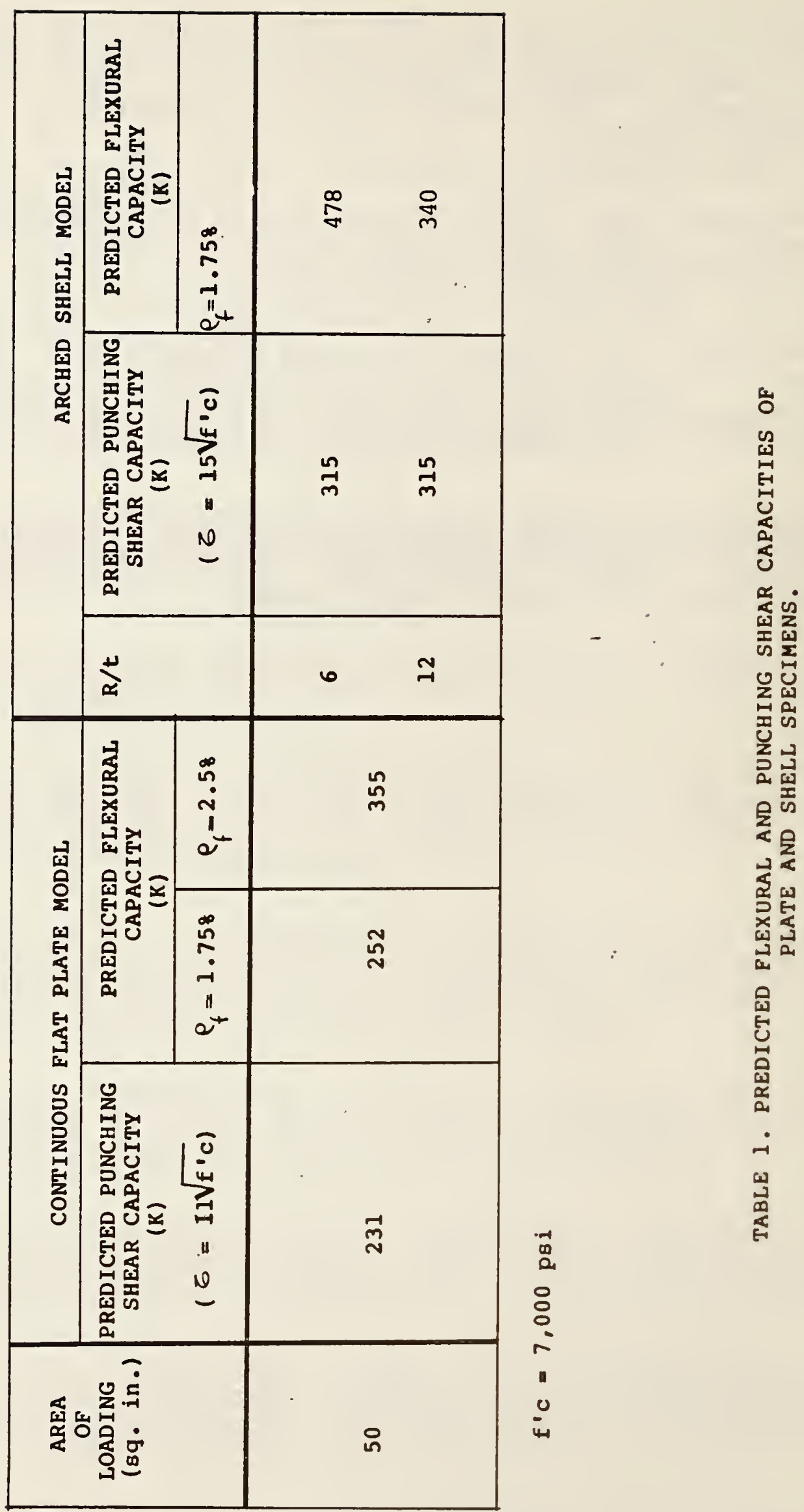




\begin{tabular}{|c|c|c|}
\hline QUANTITY & DIMENSION & $\begin{array}{l}\text { SCALE FACTOR FOR } \\
\text { PRACTICAL } \\
\text { TRUE MODEL }\end{array}$ \\
\hline Concrete stress & $\mathrm{FL}^{-2}$ & 1 \\
\hline Concrete strain & - & 1 \\
\hline Modulus of concrete & $F L^{-2}$ & 1 \\
\hline Poisson's ratio & - & 1 \\
\hline Mass density & $F L^{-3}$ & $1 / S_{\iota}$ \\
\hline Reinforcing stress & $F L^{-2}$ & 1 \\
\hline Reinforcing strain & - & 1 \\
\hline Modulus of reinforcing & $\mathrm{FL}^{-2}$ & $\therefore 1$ \\
\hline Bond stress & $F L^{-2}$ & 1 \\
\hline Linear dimension & L & $S_{\imath}$ \\
\hline Displacement & L & $S_{\iota}$ \\
\hline Angular displacement & - & 1 \\
\hline Area of reinforcement & $L^{2}$ & $s_{\imath}^{2}$ \\
\hline Concentrated load & $\mathbf{F}$ & $s_{\imath}^{2}$ \\
\hline Line load & $F L^{-1}$ & $S_{\iota}$ \\
\hline Pressure & $\mathrm{FL}^{-2}$ & 1 \\
\hline Moment & FL & $s_{\imath}^{3}$ \\
\hline
\end{tabular}

TABLE 2. SCALE FACTORS FOR MODELING REINFORCED CONCRETE STRUCTURES $[14,16]$ 


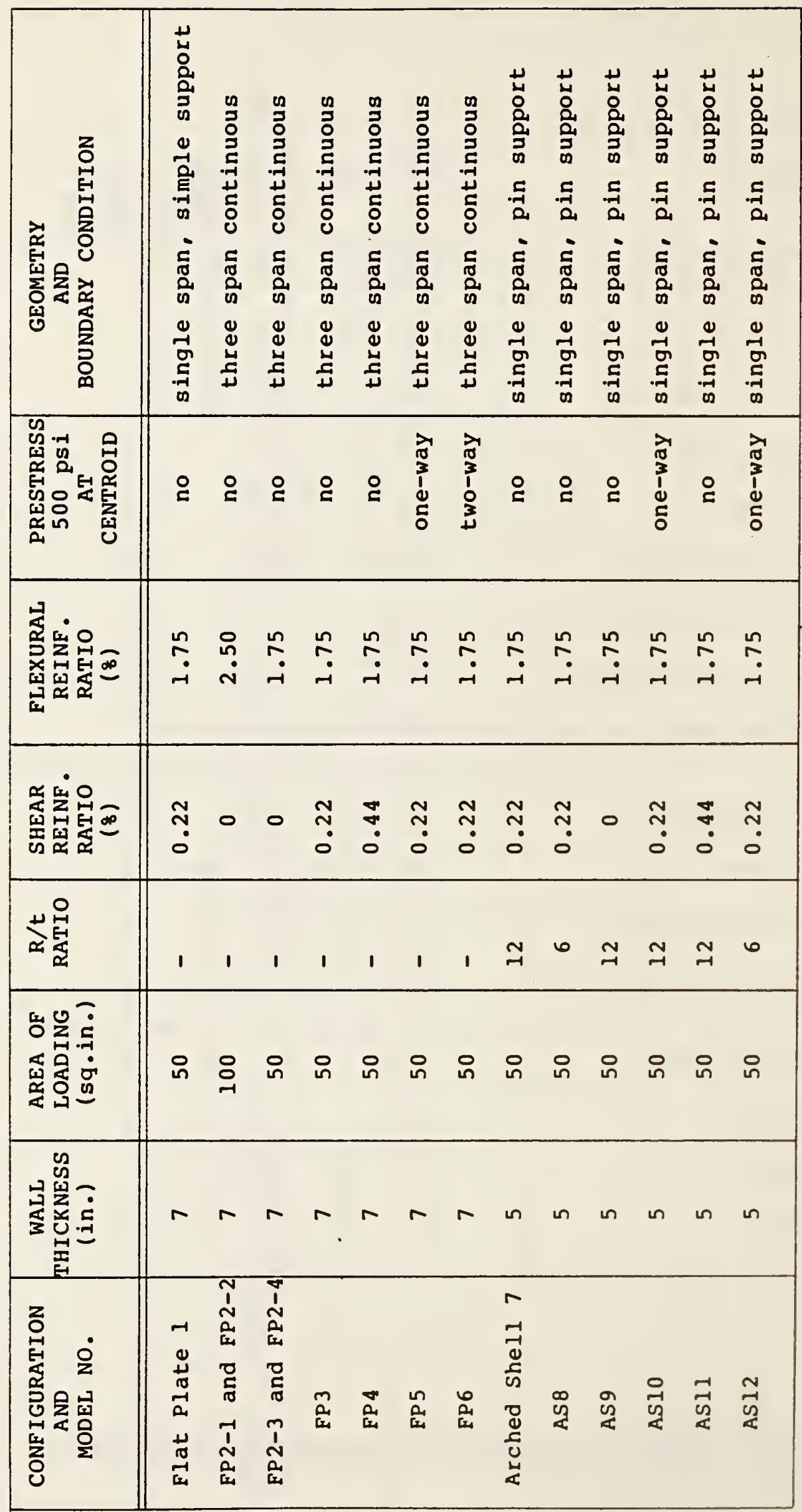

ई 


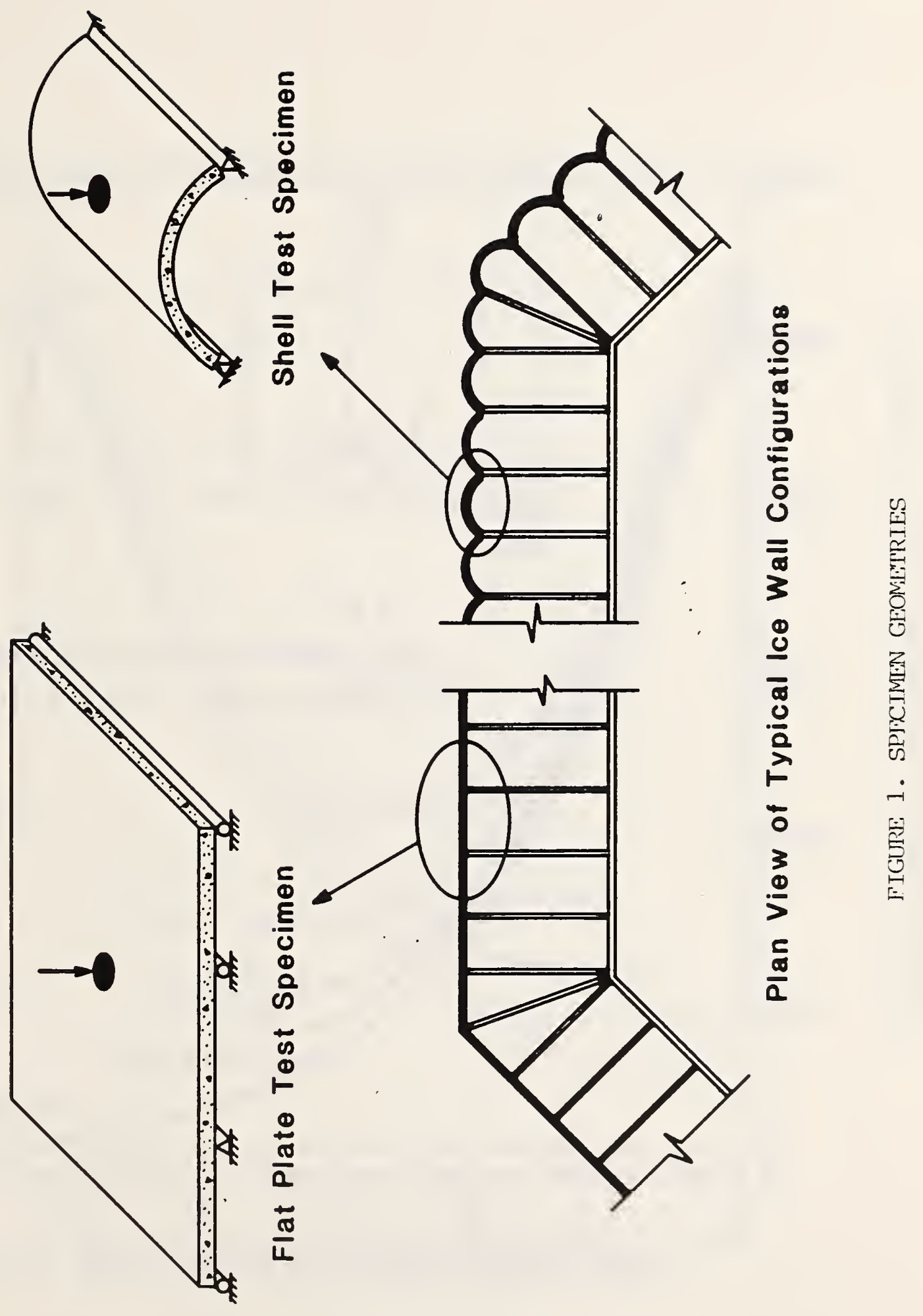




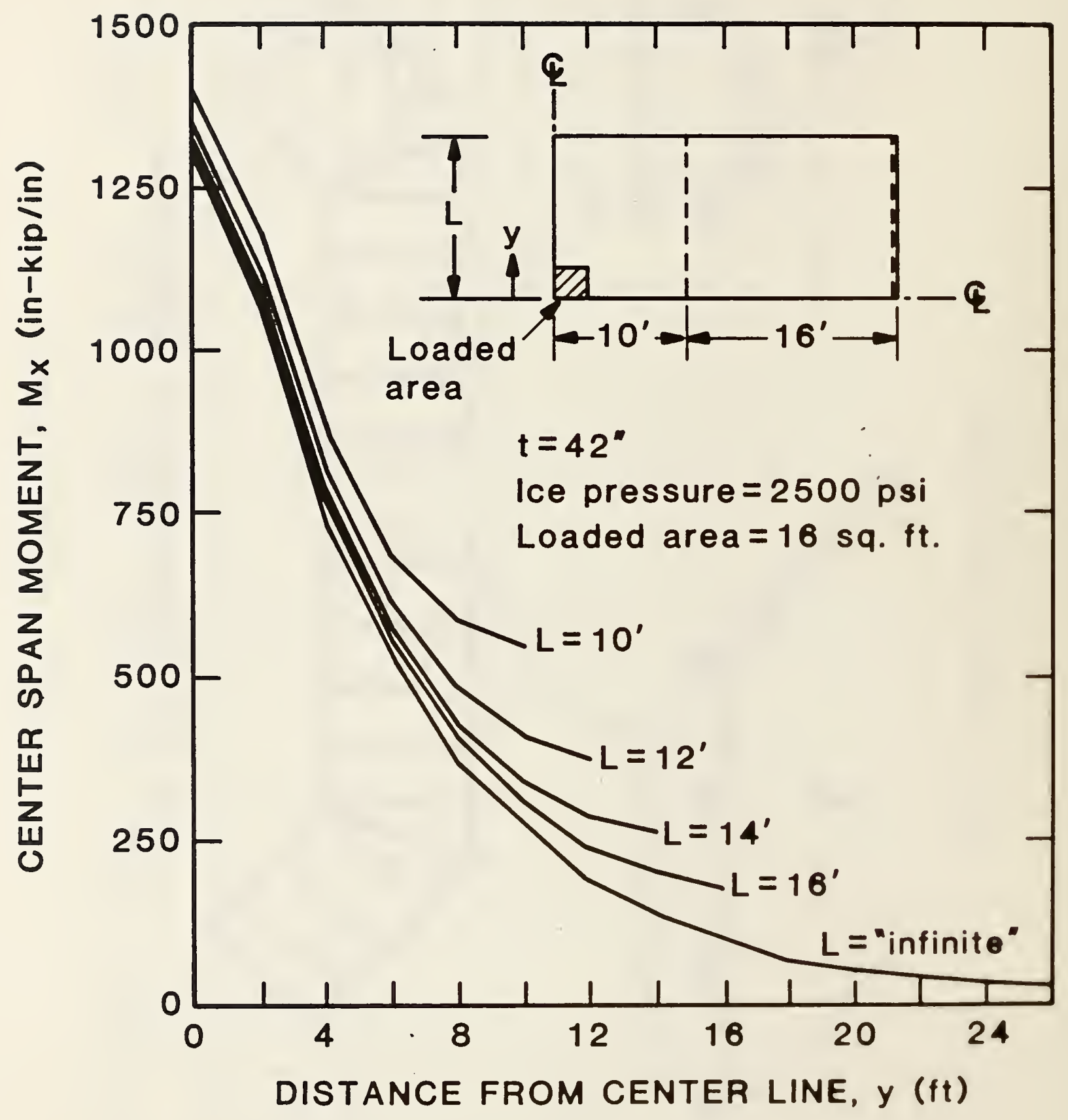

FIGURE 2. MODELING OF TRANSVERSE DINIENSION OF FLAT PLATE SPECINENS 


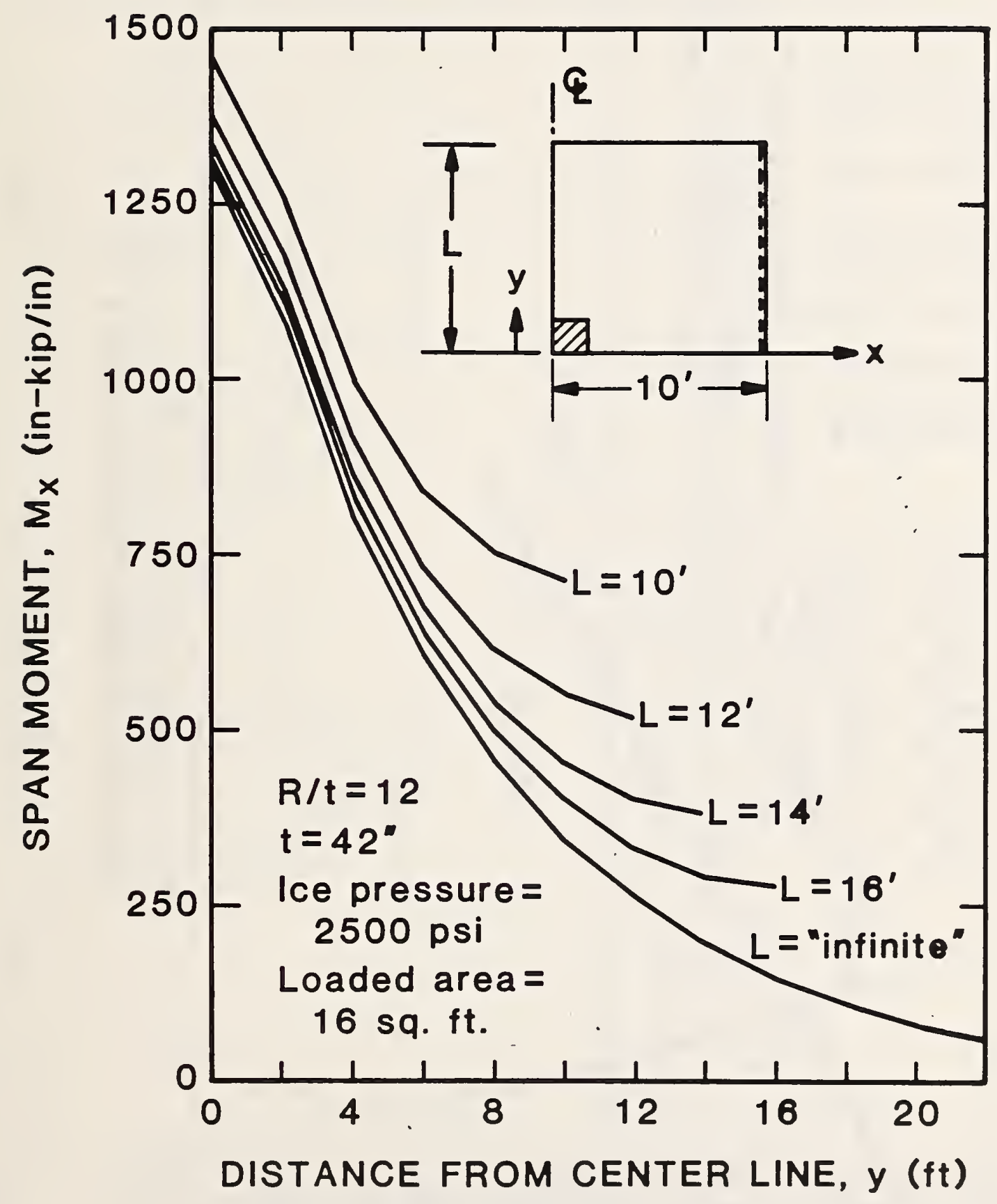

FIGURE 3. NODELTNG OF TRANSTERSE DIMENSION OF ARCHED SHEIL SPECIMENS 


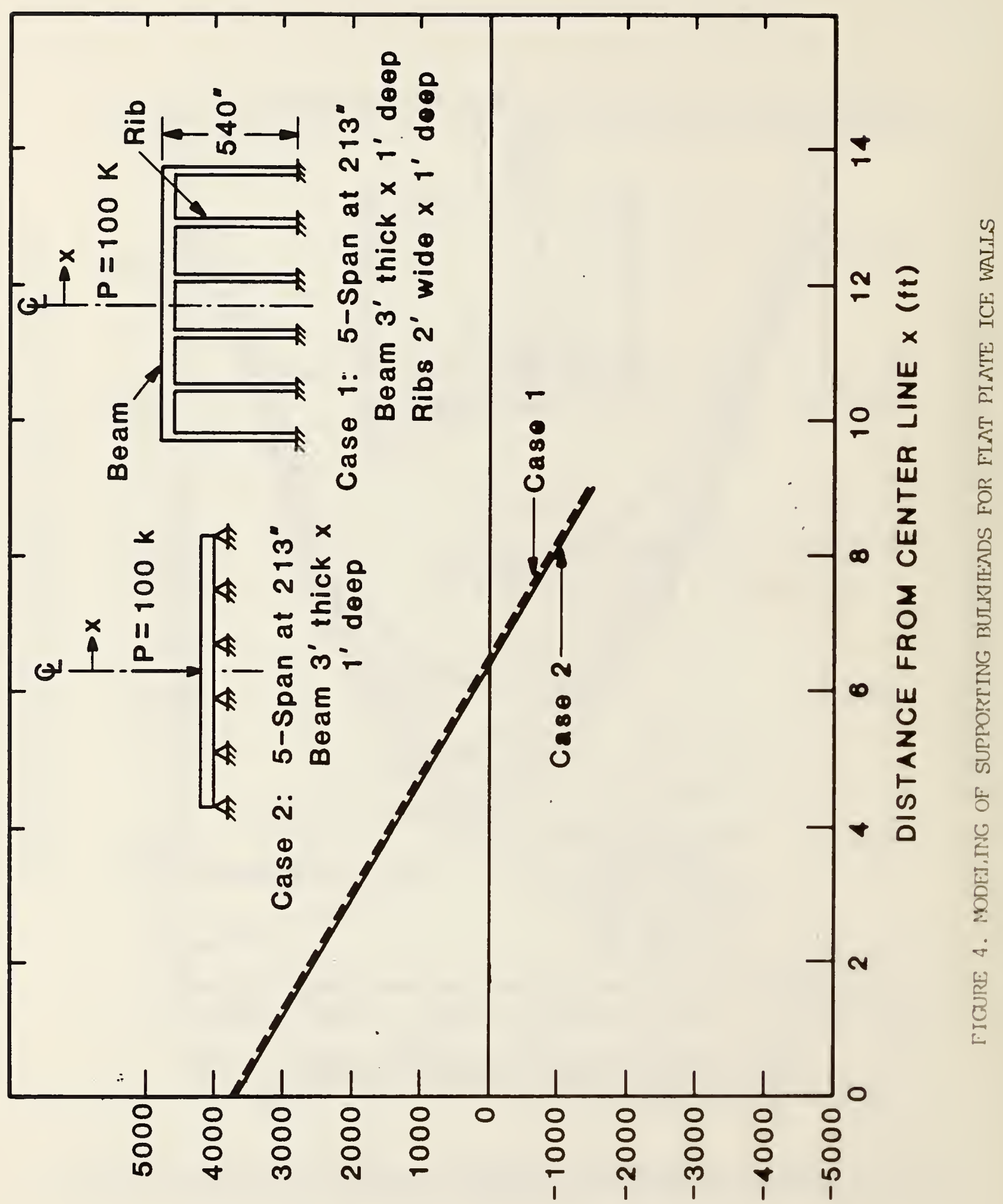

(d!Y-U!) $X W ' \perp N \exists W O W N \forall d S \quad \forall \exists \perp N \exists J$ 


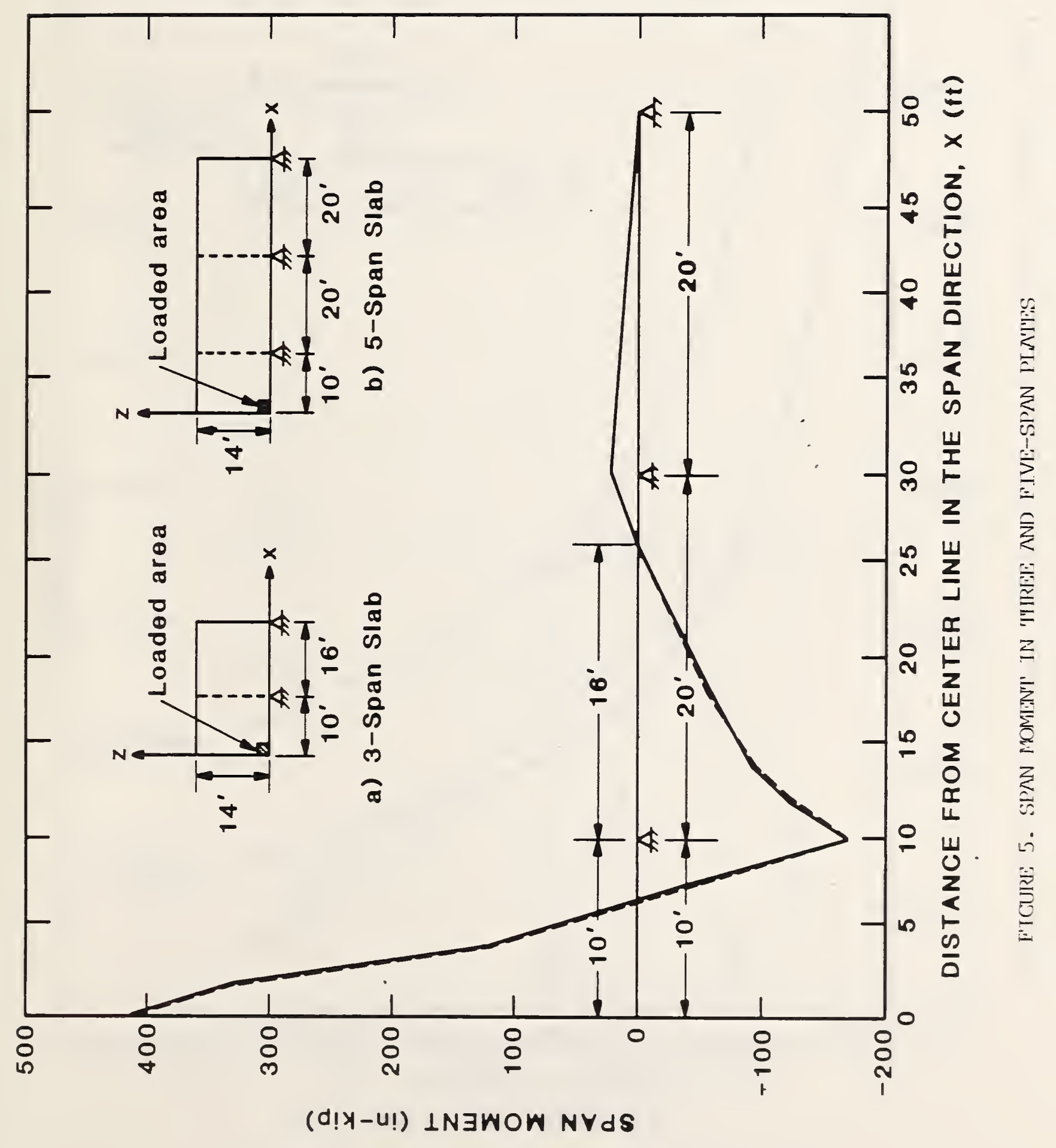




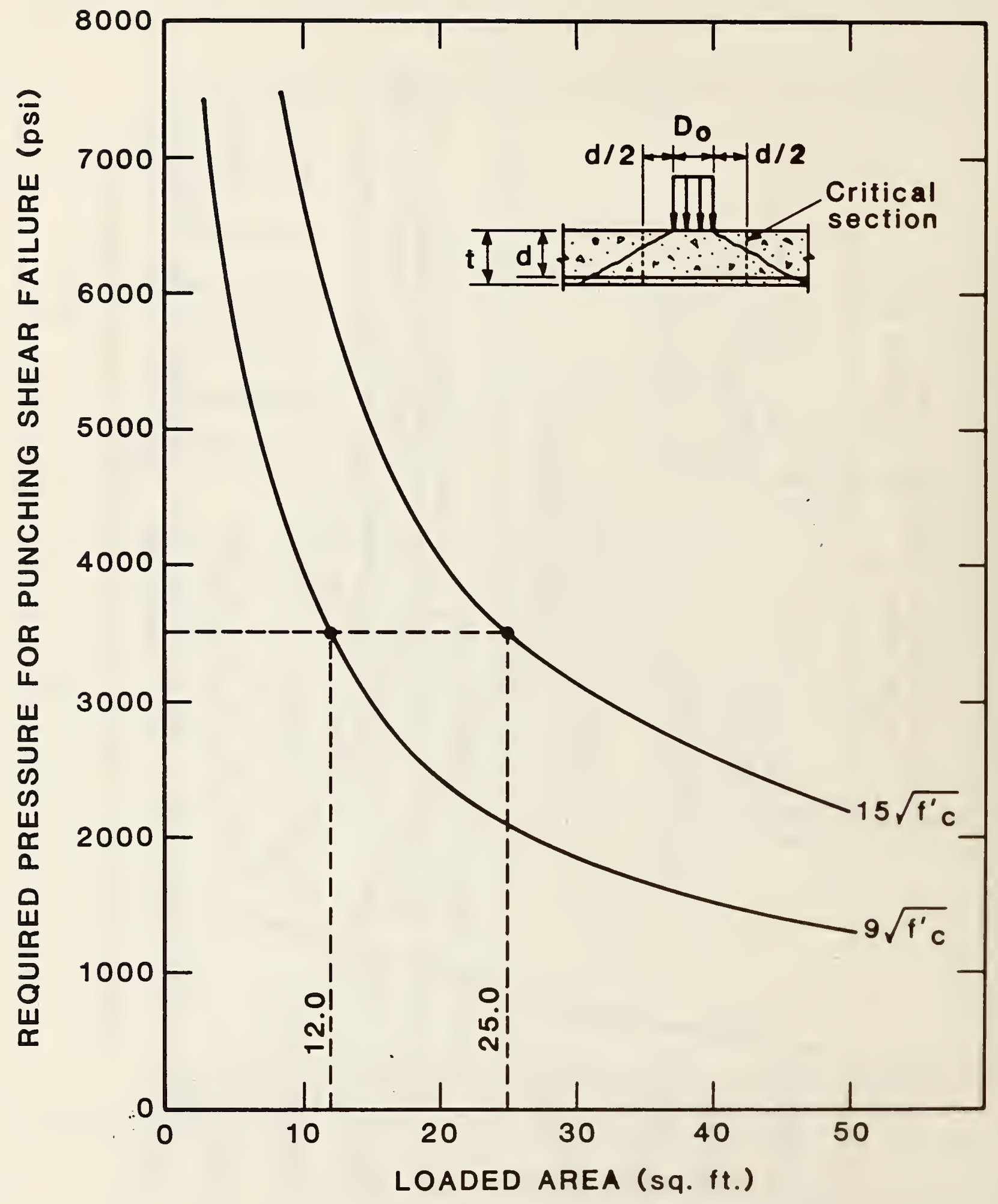

FIGURE 6. ICE CONTACT PRESSURE VS. LOADED AREA 


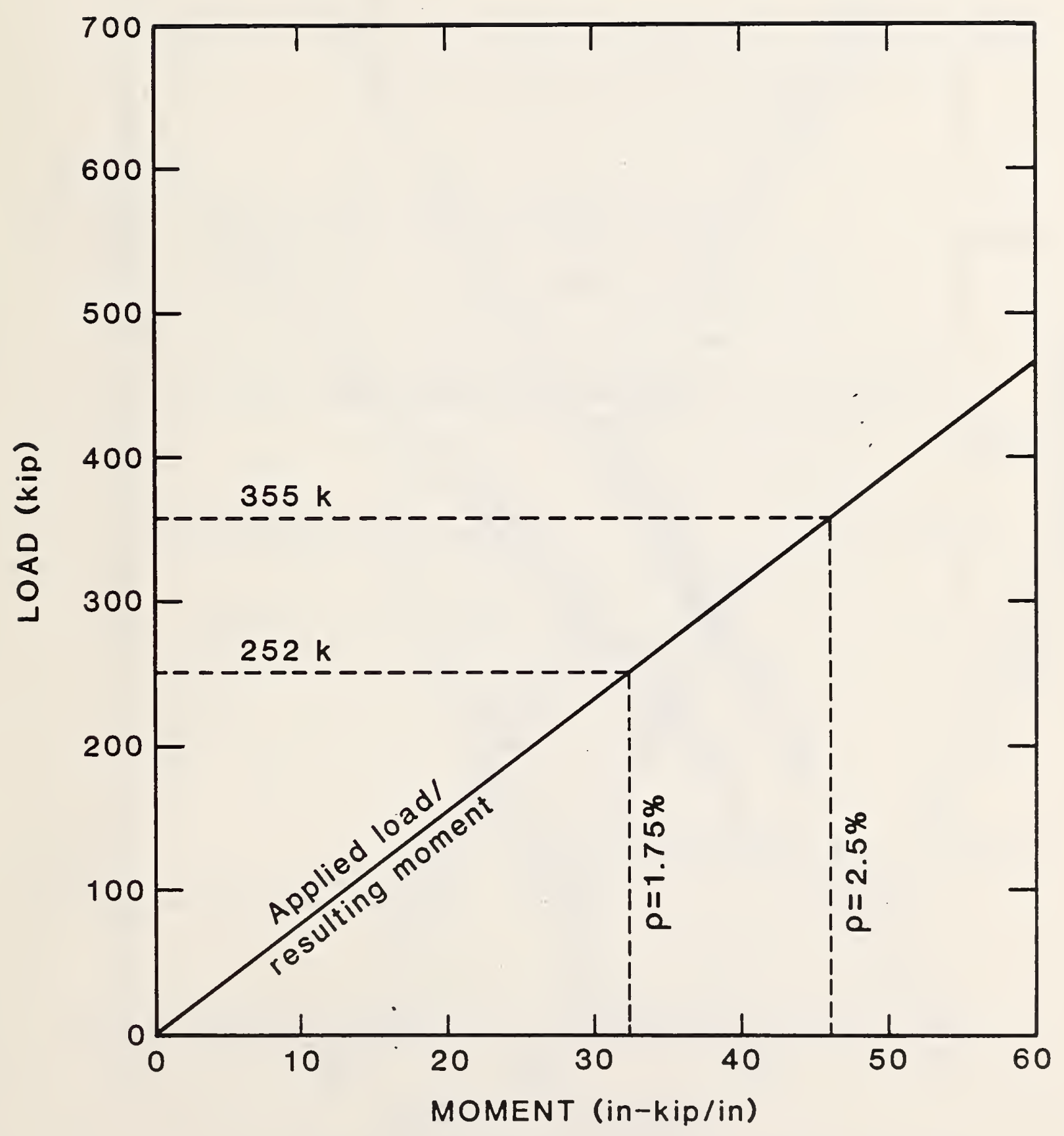

FIGLRE 7. FLEYUPAL CAPACITY OF FLAT PLATE IODEL 


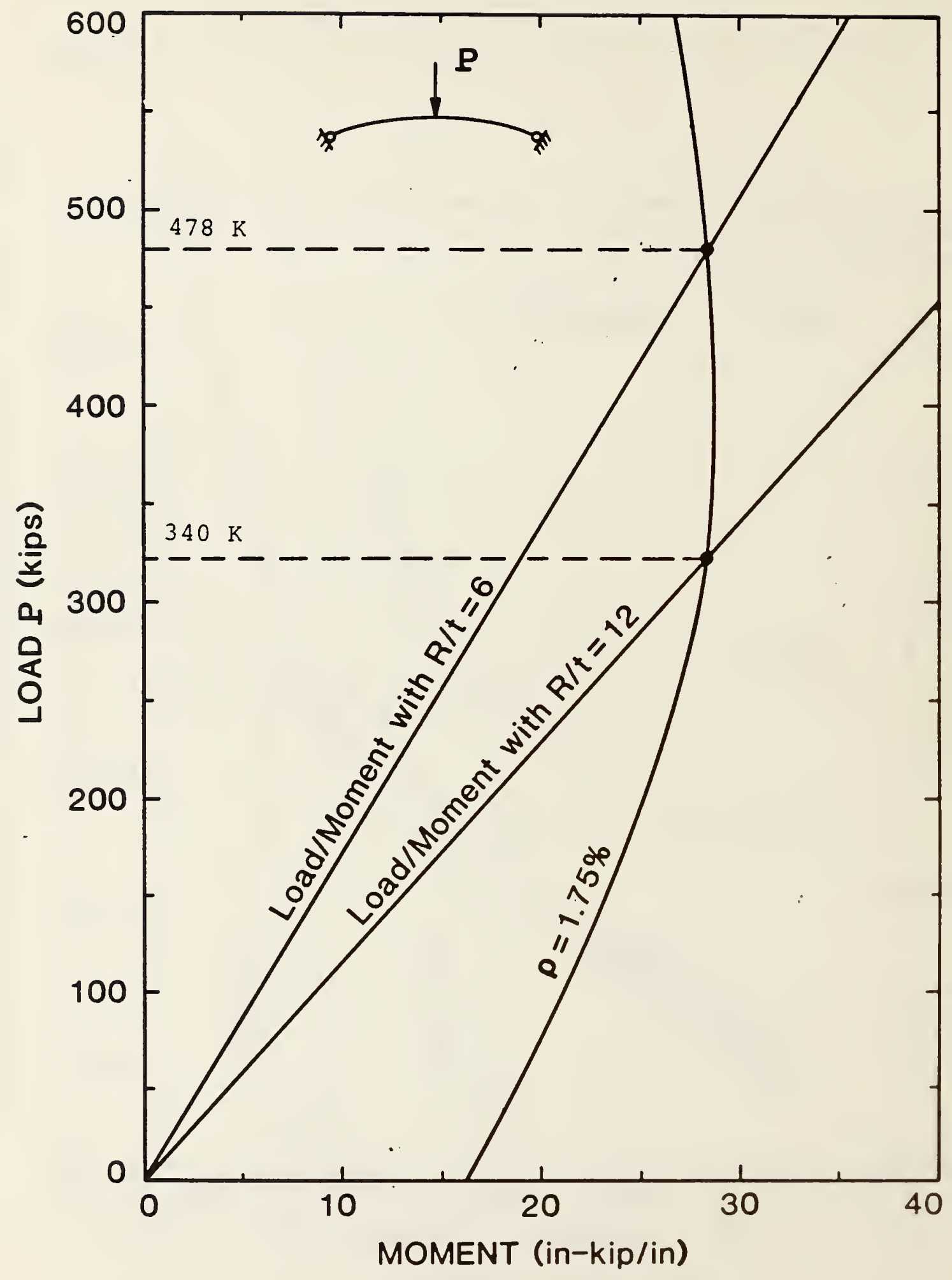

FIGURE 3. FLEXURAL CAPACITY OF ARCIIED SIIELL :ODEL 


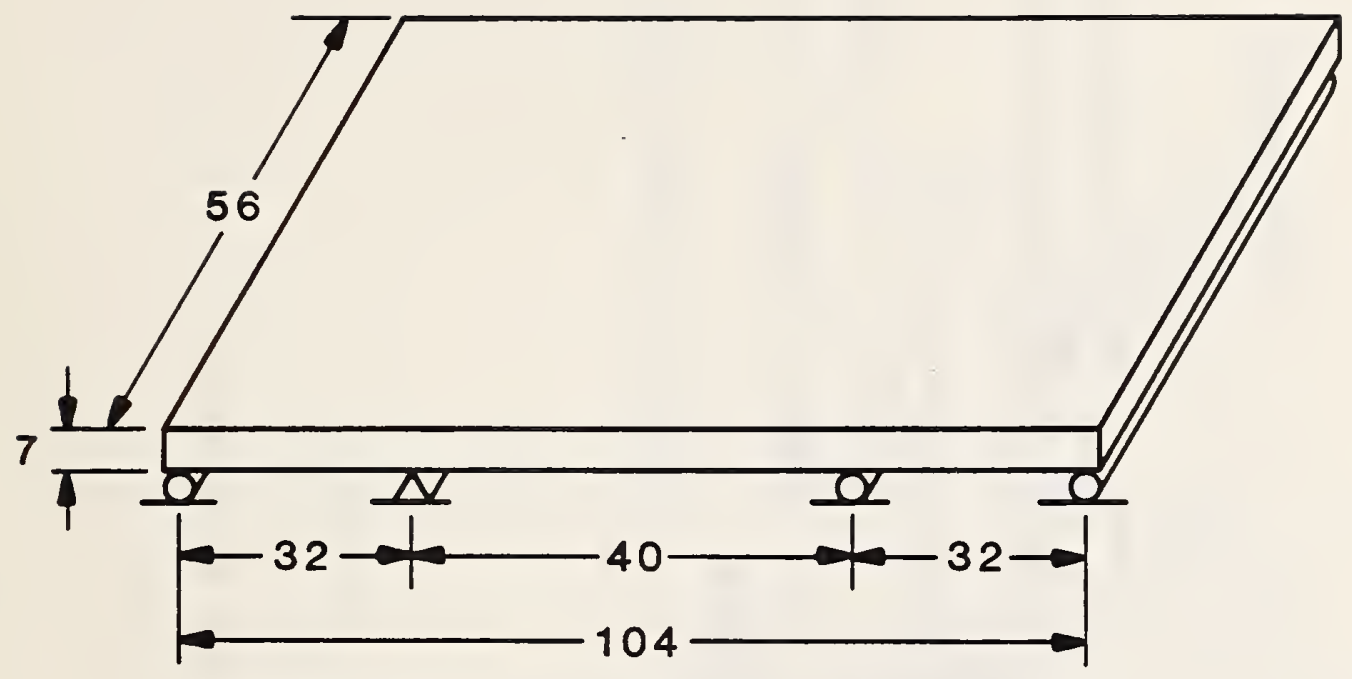

(1) Three-span continuous model

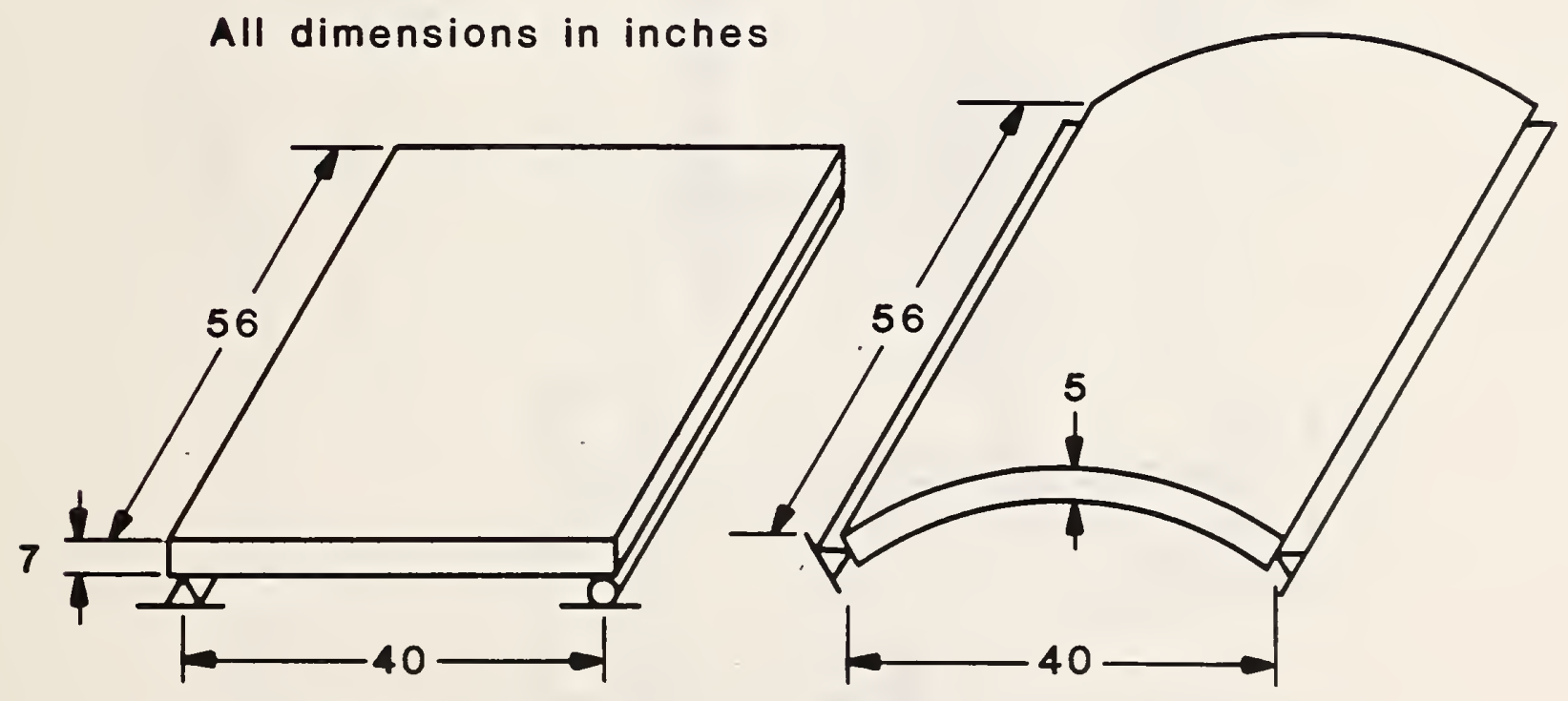

(2) single span model

(3) Arched shell model

FIGURE 9. DIMENSIONS OF 1/6-SCALE MODELS 


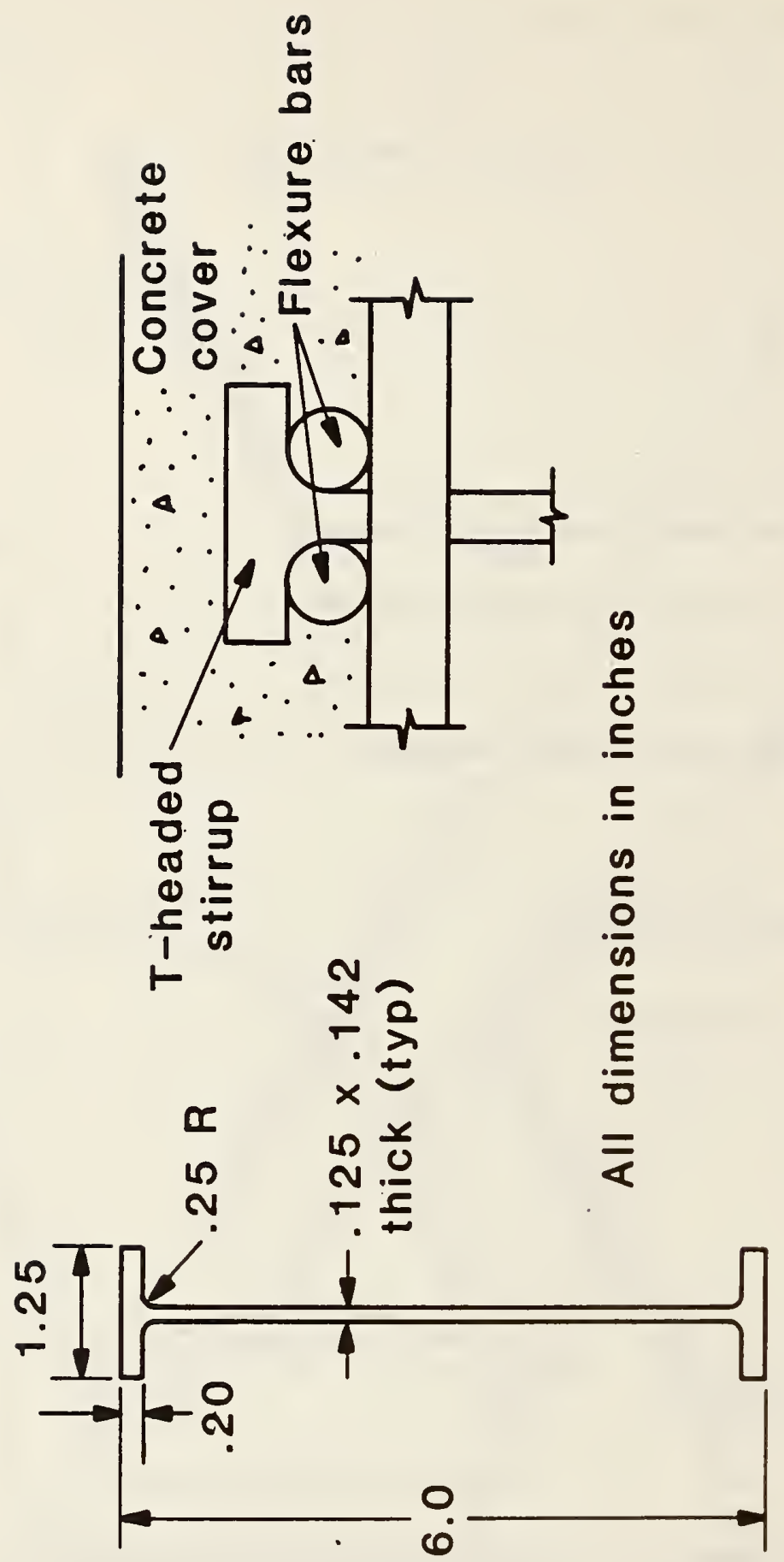




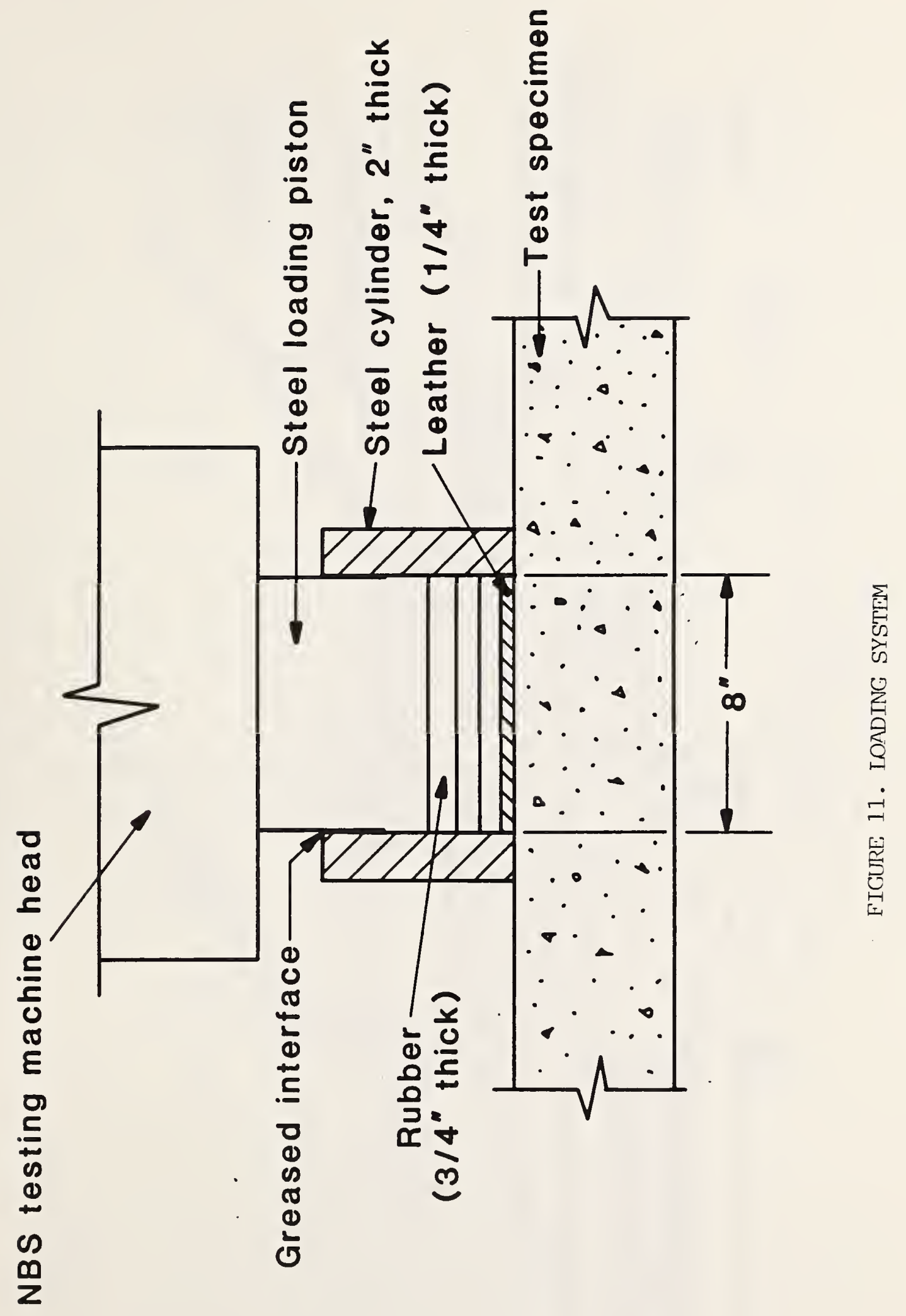




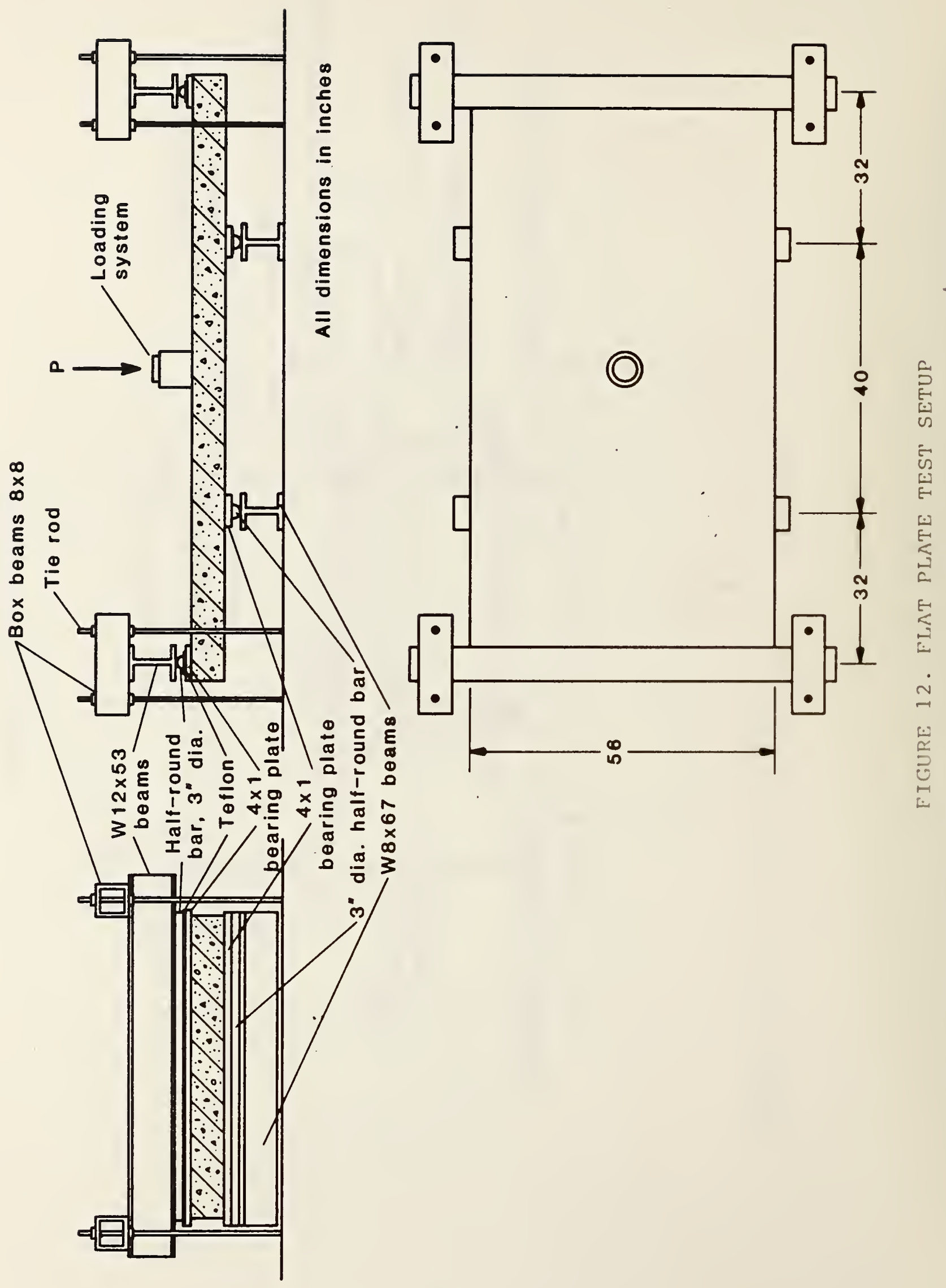




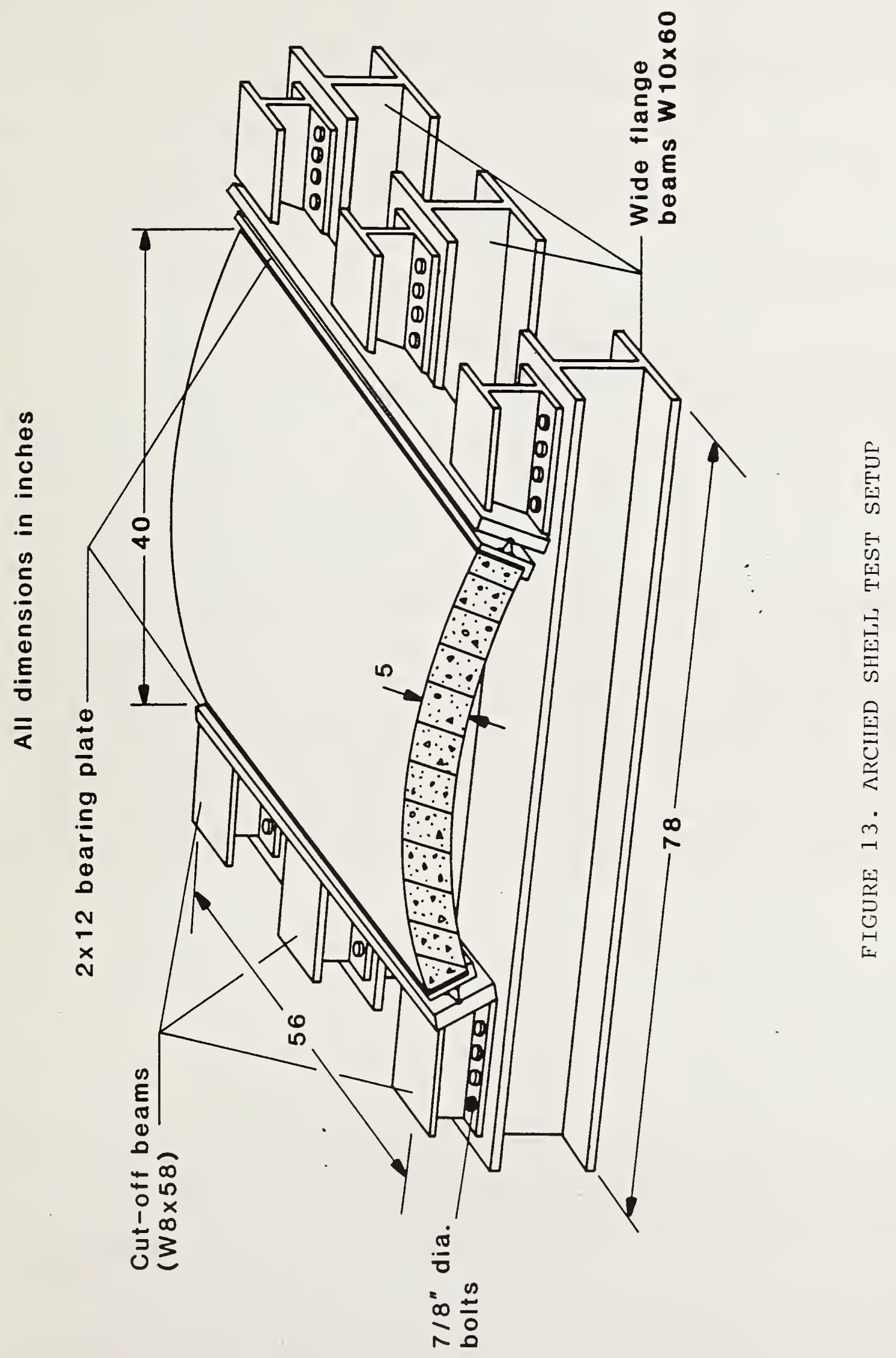


NBS-114A (REV. 2-8C)

U.S. DEPT. OF COMM.

BIBLIOGRAPHIC DATA

SHEET (See in structions)

1. PUBLICATION OR REPORT NO.

NBSIR $86-3440$

SEPTEMBER 1986

4. TITLE AND SUBTITLE

PUNCHING SHEAR RESISTANCE OF LIGHTWEIGHT CONCRETE OFFSHORE STRUCTURES FOR THE ARCTIC: Planning of Experimental Study

5. AUTHOR(S) Long T. Phan, H.S. Lew, David I. McLean

6. PERFORMING ORGANIZATION (If joint or other than NBS, see instructions)

7. Contracu Grant No.

NATIONAL BUREAU OF STANDARDS

DEPARTMENT OF COMMERCE

WASHINGTON, D.C. 20234

9. SFONSORING ORGANIZATION NAME AND COMPLETE ADDRESS (StFee!, City, State, ZIP)

Technology Assessment and Research Branch

Minerals Management Service

U.S. Department of the Interior

Reston, VA 22091

10. SUPPLEMENTARY NOTES

$\square$ Document describes a computer program; SF-185, FIPS Software Summary, is attached.

11. ABSTRACT (A 200-word or less factual summary of most significant information. If document includes a significant bibliography or literoture survey, mention it here)

This report outlines the planning for the experimental phase of an investigation currently being conducted at the National Bureau of Standards to study the punching shear behavior of heavily reinforced, thick, lightweight concrete plates and shells. The test specimens are representative of structural elements used in Arctic offshore structures. The planning includes selecting dimensions and boundary conditions, materials, reinforcing ratios and patterns, and loading procedures for the test specimens such that behavioral similarity in punching shear is achieved between representative prototype Arctic structures and the scaled models. Several factors which are considered to affect the punching shear behavior of the prototype structures will be studied.

12. KEY WORDS (Six to twelve entries; alphabetical order; capitalize only proper names; and separate key words by semicolons)

Arctic structures; experimental study; lightweight concrete; prestressing; punching shear; reinforced concrete; scale models

13. AVAILABILITY

¿ J Unlimited

X For Official Distribution. Do Not Release to NTIS

[ Order From Superintendent of Documents, U.S. Government Printing Office, Washington, D.C. 20402.
14. NO. OF

PRINTED PAGES

[] Order From National Technical Information Service (NTIS), Springfield, VA. 22161 
- 
